\title{
Prognostic value of CDCA3 in kidney renal papillary cell carcinoma
}

\author{
Hao $\mathrm{Li}^{1}$, Mi Li ${ }^{1}$, Caihong Yang ${ }^{1}$, Fengjing Guo ${ }^{1}$, Sisi Deng ${ }^{3}$, Lixi Li ${ }^{2}$, Tian Ma ${ }^{1}$ Jiyuan Yan, \\ Hua $\mathbf{W u}^{1}$, Xiaojuan $\mathrm{Li}^{2}$ \\ ${ }^{1}$ Department of Orthopedics, Tongji Hospital, Tongji Medical College, Huazhong University of Science and \\ Technology, Wuhan 430030, Hubei, China \\ ${ }^{2}$ Department of Nephrology, Tongji Hospital, Tongji Medical College, Huazhong University of Science and \\ Technology, Wuhan 430030, Hubei, China \\ ${ }^{3}$ Cancer Center, Union Hospital, Tongji Medical College, Huazhong University of Science and Technology, \\ Wuhan 430030, Hubei, China
}

Correspondence to: Xiaojuan Li; email: lixiaojuan@tjh.tjmu.edu.cn

Keywords: cell division cycle associated 3, kidney renal papillary cell carcinoma, prognostic values, differential expression, immune cell infiltration

Received: October 9, 2020

Accepted: November 22, 2021

Published: December 14, 2021

Copyright: (c) $2021 \mathrm{Li}$ et al. This is an open access article distributed under the terms of the Creative Commons Attribution License (CC BY 3.0), which permits unrestricted use, distribution, and reproduction in any medium, provided the original author and source are credited.

\section{ABSTRACT}

Kidney renal papillary cell carcinoma (KIRP) is a type of low-grade malignant renal cell carcinoma. Huge challenges remain in the treatment of KIRP. Cell division cycle associated 3 (CDCA3) participates in human physiological and pathological processes. However, its role in KIRP has not been established. Here, we evaluated the prognostic value of CDCA3 in KIRP using a comprehensive bioinformatics approach. Data for CDCA3 expression in KIRP were obtained from online database. Different expression genes between high and low CDCA3 expression groups were identified and evaluated by performing Gene ontology and Kyoto Encyclopedia of Genes and Genomes pathway enrichment analyses. A gene set enrichment analysis was performed to elucidate the function and pathway differences between the different. Differences in immune cell infiltration between low and high CDCA3 expression groups were analyzed by a single-sample GSEA method for immune cells. A protein-protein interaction network was generated and hub genes were identified. UALCAN was used to analyze associations between the mRNA expression levels of CDCA3 in KIRP tissues with clinicopathologic parameters. The diagnostic efficacy of CDCA3 for KIRP was analyzed by ROC analysis. Logistic regression was used to analyze relationships between the clinicopathological characteristics and CDCA3 expression. Our results indicated that high CDCA3 mRNA expression is significantly associated with some clinicopathologic parameters in KIRP patients High CDCA3 mRNA expression associated with a shorter overall survival, progression-free interval, and disease-special survival. Taken together, CDCA3 is a potential target for the development of anti-KIRP therapeutics and is an efficient prognostic marker.

\section{INTRODUCTION}

Renal cell carcinoma (RCC) is one of the most common malignant tumors of the urinary system, and its morbidity and mortality are on the rise worldwide [1]. Kidney renal papillary cell carcinoma (KIRP), also known as papillary renal cell carcinoma (PRCC), is a type of low-grade malignancy that originates from renal tubular epithelial cells [2], accounting for about 10-20\% of RCC cases [3-6]. KIRP grows slowly and has a better prognosis than those of other types of RCC.

Currently, imaging examinations such as ultrasound, computed tomography (CT), and magnetic resonance imaging (MRI) are used to diagnose KIRP, however, these approaches do not show sufficient specificity [7]. 
Therefore, the pathological examination remains the gold standard $[8,9]$. Nephrectomy and nephron-sparing surgery are still the main treatments for KIRP. Chemotherapy and targeted drugs exert certain effects in advanced metastatic KIRP, however, the efficacy of these approaches remains controversial [3, 4]. In addition, the cost of the KIRP diagnosis and treatment imposes a heavy burden to individuals and society.

Although KIRP has a low rates of metastasis and recurrence $[10,11]$, prognosis, especially for patients with advanced disease, is very poor due to occurrence of distant metastasis [12]. Owing to the lack of clinical symptoms, KIRP is usually found on physical examination. A high tumor volume is associated with cystic changes, necrosis, bleeding, and calcification [13]. Therefore, the identification of credible predictors related to the stage and prognosis of KIRP will help to provide new targets for treatment, diagnosis, and prognostic evaluation. Various biomarkers associated with KIRP progression and prognosis have been reported [14-16], however, their credibility remains controversial.

Gene encoding CDCA3 is located on chromosome $12 \mathrm{p} 12$ and the protein is composed of 268 amino acids with a molecular weight of $29 \mathrm{kDa}$. CDCA 3 contributes to human physiological and pathological processes by regulating various downstream cytokines. Studies have shown that CDCA3 plays an important role in the development of various tumors [17-19]. However, little is known about the role of CDCA3 in the KIRP development.

In this study, we addressed this issue by identifying the transcriptional expression patterns of CDCA3 based on The Cancer Genome Atlas (TCGA) database and the Genotype-Tissue Expression (GTEx) database. We further evaluated Gene Ontology (GO) functions and Kyoto Encyclopedia of Genes and Genomes (KEGG) pathways of CDCA3 related to CDCA3 and associated differential expression genes (DEGs) in KIRP. Furthermore, we performed a gene set enrichment analysis (GSEA), immune infiltration analysis, proteinprotein interaction (PPI) network analysis, clinicopathologic analysis, and analyzed the prognostic value of CDCA3 in KIRP. Our study clarify the biological functionality and prognostic value of CDCA3, which is expected to be beneficial for the diagnosis and treatment of KIRP.

\section{MATERIALS AND METHODS}

\section{Differential expression of CDCA3}

The TCGA database was used to investigate CDCA3 expression in patients with KIRP and analyze the association between expression levels and the prognosis. In total, 320 samples were selected as the TCGA cohort including 288 KIRP samples and 32 normal samples. Level 3 high-throughput RNAsequencing data and corresponding clinical information data were downloaded from the KIRP project of the TCGA GDC data portal. RNAseq data in FPKM (fragments per kilobase per million) format were converted into TPM (transcripts per million reads) format for comparisons of CDCA3 expression levels between samples. The Wilcoxon rank-sum test was used to compare the gene expression levels of CDCA3 in 32 normal samples and 288 KIRP samples and between 31 KIRP samples and the paired adjacent normal tissues were compared. Results with $P<0.001$ were considered statically significant.

RNAseq data were downloaded in TPM format from UCSC XENA (https://xenabrowser.net/datapages/), and these data were processed in a unified way through the Toil process [20] from TCGA and GTEx database. The expression of CDCA3 in normal samples of the GTEx database and TCGA database was compared with corresponding 33 types of cancer samples including KIRP in TCGA by Wilcoxon rank-sum test. Results with $P<0.001$ were considered statically significant.

\section{DEGs associated with CDCA3 in KIRP}

According to the median expression levels of CDCA3 (TPM values) in KIRP from TCGA database, all KIRP samples were divided into two groups: CDCA3-high expression group and CDCA3-low expression group. The DESeq2 package [21] was used to analyze the DEGs correlated with CDCA3 expression in KIRP from the TCGA database by using RNA-seq count data downloaded from the GDC data portal.

\section{GO and KEGG pathway enrichment analyses}

Metascape (http://metascape.org) was used to analyze the functional and pathway enrichment of DEGs and generate PPI networks associated with CDCA3 alterations in KIRP. GO and KEGG pathways enrichment was analyzed using Metascape [22]. $P$ < 0.01 , a minimum count of 3 , and the enrichment factor $>1.5$ were thresholds for statistical significance.

\section{Gene set enrichment analysis (GSEA)}

GSEA [23] was performed using $\mathrm{R}$ package clusterProfiler (3.8.0) to elucidate the significant functional and pathway differences between the CDCA3-low expression group and the CDCA3-high expression group [24]. The h.all.v7.0.symbols.gmt file in MSigDB Collections was selected as the reference 
gene collection. The number of gene set permutations was 1,000 for each analysis. NES absolute value $>=1$, adjusted $P$-value $<0.05$, and FDR $<0.25$ were considered to be statistically significant.

\section{Immune cell infiltration analysis by ssGSEA}

Immune cell infiltration analysis was analyzed by a ssGSEA for 24 types of immune cells in tumor samples [25]. These 24 types of immune cells comprised macrophages, neutrophils, B cells, cytotoxic cells, T cells, CD8+ T cells, NK cells, NK CD56bright cells, NK CD56dim cells, mast cells, eosinophils, dendritic cells (DCs), activated DCs (aDCs), plasmacytoid DCs (pDCs), immature DCs (iDCs), T helper cells (Th), Th1 cells, Th2 cells, Th7 cells, Regulatory T cells (Treg), T gamma delta (Tgd), $\mathrm{T}$ central memory $(\mathrm{Tcm}), \mathrm{T}$ effector memory (Tem) and $\mathrm{T}$ follicular helper (Tfh). The correlations between CDCA3 expression and these immune cell frequencies were analyzed by Spearman correlation coefficients, and the infiltration of immune cells was compares between the CDCA3-low group and CDCA3-high group by the Wilcoxon rank-sum test.

\section{PPI network analysis}

The STRING database (Search Tool for the Retrieval of Interacting Genes) (http://string-db.org) was used to analyze the functional interactions between proteins [26]. The PPI networks were constructed using Cytoscape based on STRING with a threshold for interaction score of 0.7. The most significant module in the PPI network was identified by MCODE (Molecular Complex Detection) embedded in Cytoscape to identify densely connected regions. The criteria for selection were as follows: degree cut-off $=2$, node score cut-off $=$ 0.2 , Max depth $=100$ and $\mathrm{k}$-score $=2$.

\section{Clinicopathological analysis of CDCA3 in KIRP}

UALCAN was used to analyze the associations between the mRNA expression level of CDCA3 in KIRP tissues with their clinicopathologic parameters, such as clinical stage, patient's gender, race, age, smoking status, serum calcium, hemoglobin, laterality and MET status. The results were obtained directly by selecting the clinicopathological grouping options integrated into the UALCAN database. Only the tumor group could be divided into different clinicopathological groups. $P<$ 0.05 indicated significance.

\section{Receiver operating characteristic (ROC) curve}

The AUC of the ROC curve was generated to evaluate the predictive value of the gene. AUC values closer to
1.0 indicated a better diagnosis, $0.5 \sim 0.7$ indicated a low predictive value, $0.7 \sim 0.9$ indicated moderate predictive accuracy, and $>0.9$ indicated a high accuracy. The abscissa was the false positive rate (FPR), and the ordinate was the true positive rate (TPR).

\section{Survival analysis}

The prognostic value of the CDCA3 mRNA expression level in KIRP was analyzed using the survminer package of $\mathrm{R}$. Based on the median values of CDCA3 expression (TPM), patients with KIRP were divided into CDCA3-low expression group and CDCA3-high expression group. Results with $P<0.05$ were considered statically significant.

\section{Ethics statement}

As all data used in this study were obtained from the TCGA database. Hence, ethics approval and informed consent were not required. Our study was performed in accordance with the publication guidelines of TCGA.

\section{Statistical analyses}

All statistical analyses and the generation of plots were performed using $\mathrm{R}$ (v.3.5.1). The Wilcoxon rank-sum test and Wilcoxon signed-rank test were used to compare the expression of CDCA3 in unpaired samples and paired samples, respectively. The Kruskal-Wallis test, Wilcoxon signed-rank test, and logistic regression were used to evaluate the relationships between clinical-pathologic features and CDCA3 expression. Cox regression analyses and the Kaplan-Meier method were used to evaluate prognostic factors. A multivariate Cox analysis was used to evaluate the impact of CDCA3 expression on survival along with other clinical traits.

\section{RESULTS}

\section{Overexpression of CDCA3 in patients with KIRP}

We analyzed CDCA3 expression in normal samples from the GTEx database and the TCGA and 33 tumor samples in TCGA. CDCA 3 expression was significantly up-regulated in bladder urothelial carcinoma, cervical squamous cell carcinoma and adenocarcinoma, KIRP, KIRC, and other cancer types (Figure 1A). An analysis of various tumors and the paired paracancerous tissues in TCGA showed that the expression of CDCA3 in bladder urothelial carcinoma, KIRP, hepatocellular carcinoma and other cancers was significantly higher than those in corresponding paracancerous tissues (Figure 1B). 
To detect the differences in the CDCA3 mRNA expression level between tumor and non-cancerous tissues, RNAseq data for 288 KIRP samples and 32 normal samples were analyzed. As was shown in Figure
1C, CDCA3 mRNA expression level were significantly higher in KIRP samples than in normal tissues. The upregulation of CDCA3 mRNA expression was also observed in KIRP tissues compared to that in paired

A

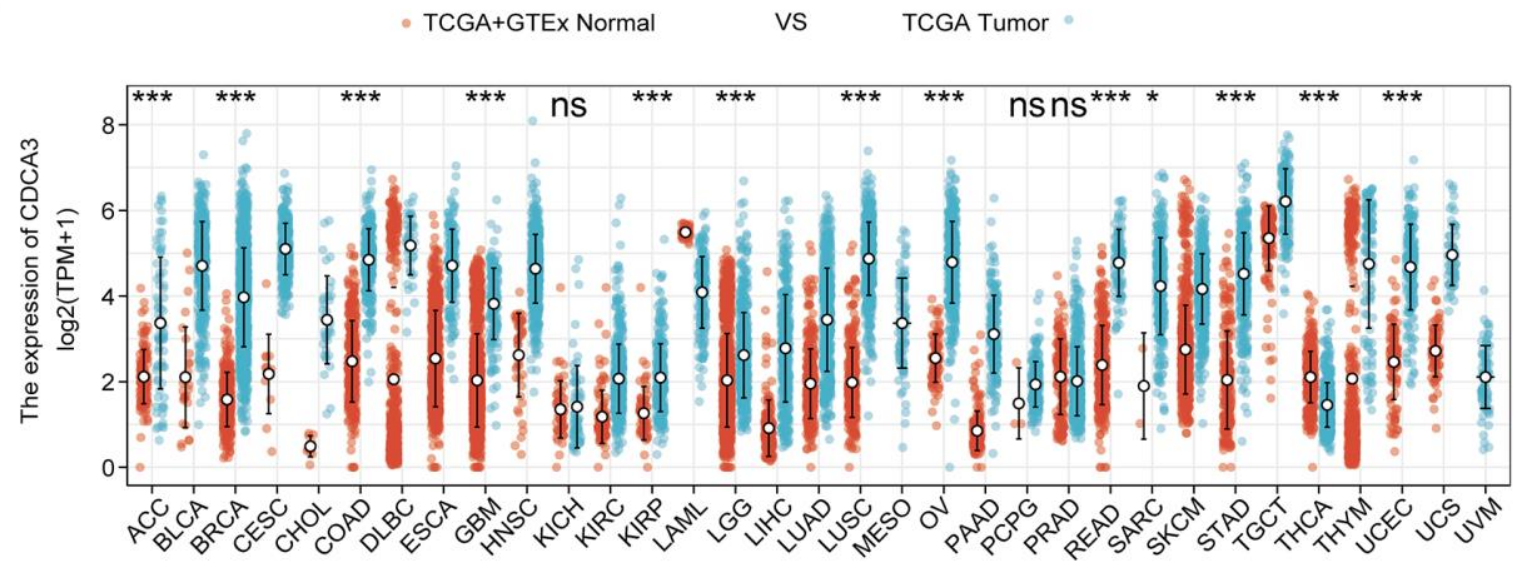

B

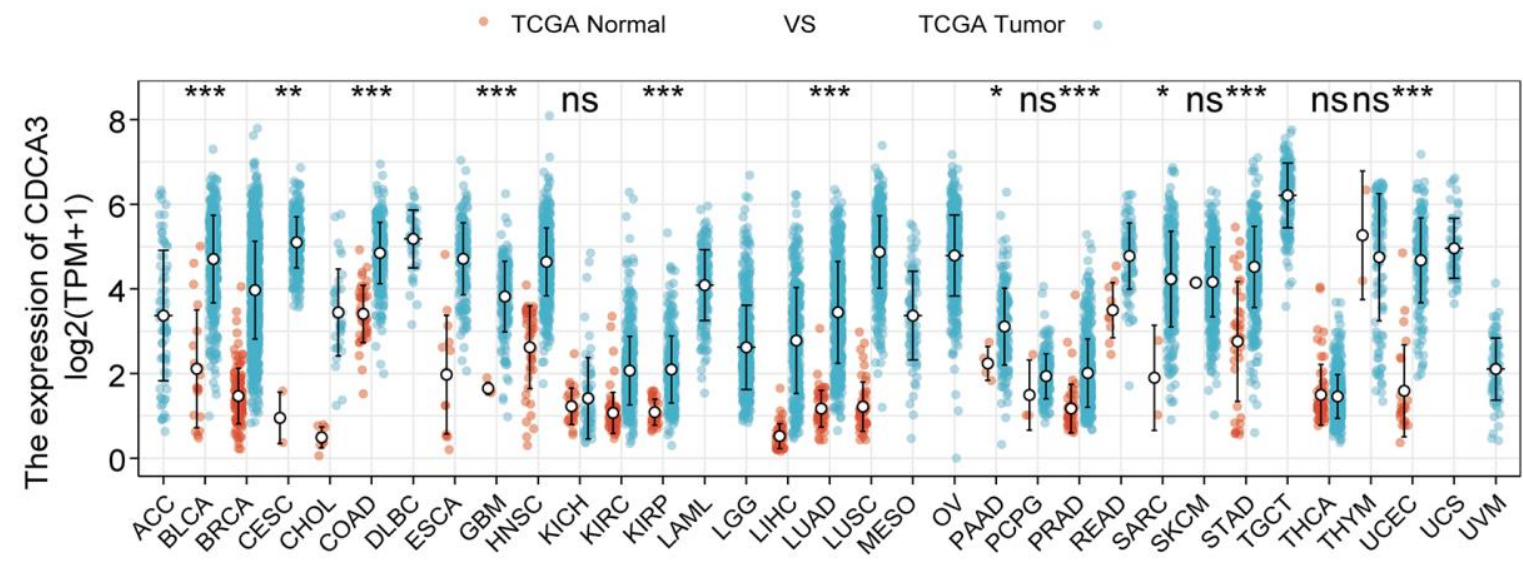

C

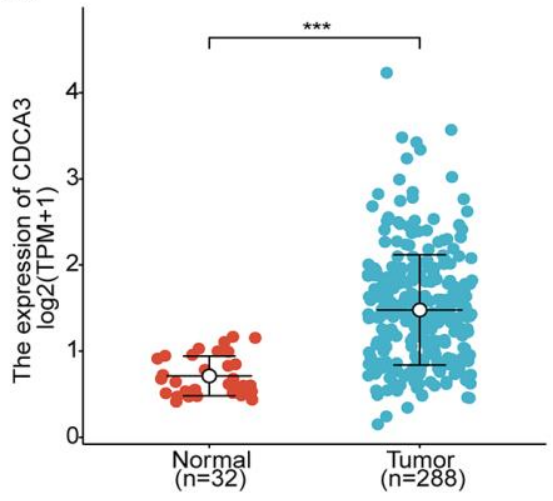

D

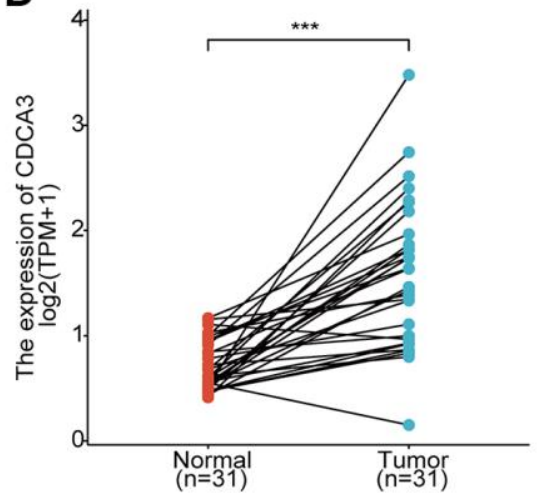

E

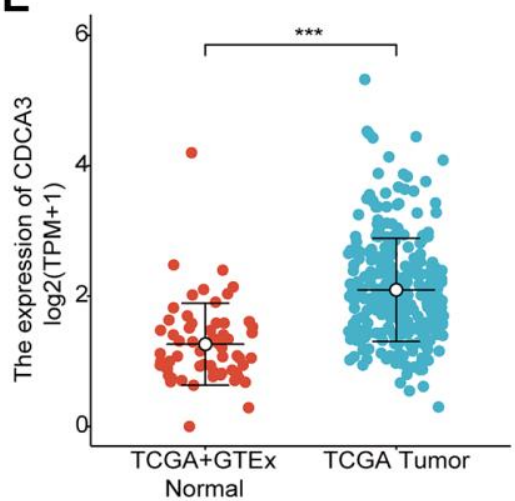

Figure 1. Overexpression of CDCA3 in patients with KIRP. (A) CDCA3 expression in normal samples from the GTEx database and the TCGA and 33 tumor samples in TCGA. ns, $p \geq 0.05 ;{ }^{*}, p<0.05 ;{ }^{* *}, p<0.01 ; * * *, p<0.001$. (B) CDCA3 expression in 33 tumor samples in TCGA and paired paracancerous tissues in TCGA. ns, $p \geq 0.05 ; *, p<0.05 ; * *, p<0.01 ; * * *, p<0.001$. (C) CDCA3 mRNA expression level in $288 \mathrm{KIRP}$ samples and 32 normal samples. ${ }^{* * *} p<0.001$. (D) CDCA3 mRNA expression in KIRP tissues and in paired paracancerous normal samples. ${ }^{* * *}$ $p<0.001$. (E) CDCA3 mRNA expression in normal samples and KIRP from the GTEx database and TCGA. ${ }^{* * *} p<0.001$. 
paracancerous normal samples (Figure 1D). Furthermore, based on expression data for normal samples from the GTEx database and TCGA as well as KIRP samples from TCGA, CDCA3 was significantly overexpressed in KIRP (Figure 1E).

These results indicated that the expression of CDCA3 is up-regulated in various types of tumor tissues, including KIRP, in which it is significantly overexpressed compared with levels in normal kidney tissues or paired paracancerous normal samples.

\section{DEGs associated with CDCA3 in KIRP}

We identified DEGs or co-expressed genes associated with CDCA3 in KIRP by identifying genes that differed in expression between the groups with high and low CDCA3exression. We detected 739 DEGs with | $\log F C$ $\mid>1.5$ and $p$ adj $<0.05$ between groups. A volcano graph was generated to visualize the results of the DEGs analysis. Among the DEGs, 565 had $\operatorname{logFC}>1.5$ and padj $<0.05$, and 174 had $\operatorname{logFC}<-1.5$ and $p$ adj $<0.05$ (Figure 2A). As shown in Figure 2B, the expression level of AURKB, NUF2, HJURP, KIF18B and TROAP were significantly up-regulated in high CDCA3 expression group compared with the low CDCA3 expression group, while the expression level of CETP, HS3ST2, CYP17A1, CHIT1 and LHCGR were significantly down-regulated in the CDCA3 highexpression group.

\section{GO and KEGG pathway enrichment analyses}

Functional and pathway enrichment analyses of DEGs associated with CDCA3 were analyzed using

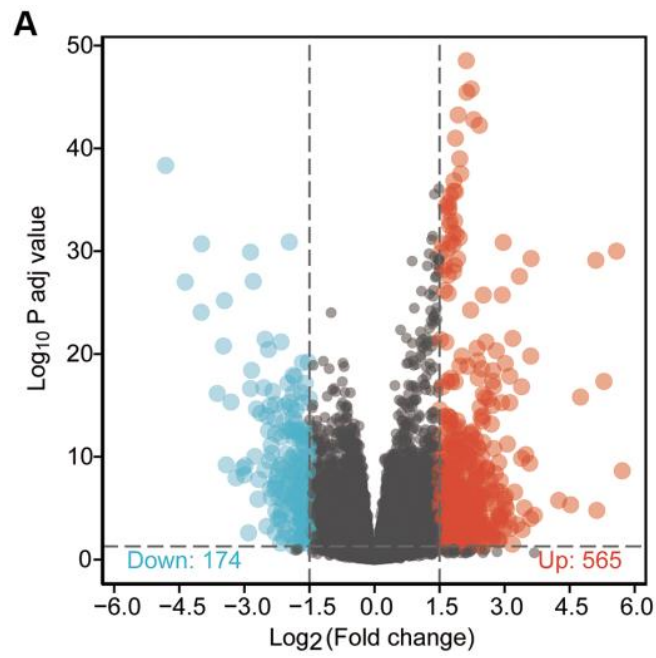

Metascape. Various biological processes, such as GO: 0007389 (pattern specification process), GO: 0048285 (organelle fission), GO: 0000280 (nuclear division), GO: 0003002 (regionalization), GO: 0140014 (mitotic nuclear division), GO0001708 (cell fate specification), GO: 0048663 (neuron fate commitment) and GO: 0048665 (neuron fate specification) were significantly associated with alterations in CDCA3 expression (Figure 3A). Additionally, genes associated with CDCA3 were enriched for various cellular components, including GO: 1990351 (transporter complex), GO: 1902495 (transmembrane transporter complex), GO: 0016324 (basolateral plasma membrane), GO: 0034702 (ion channel complex), GO: 0030496 (midbody), GO: 000779 (condensed chromosome, centromeric region), GO: 1902710 (GABA receptor complex) and GO: 1902711 (GABA-A receptor complex) were remarkably regulated by the CDCA3 in KIRP (Figure 3B). CDCA3 also prominently affected the molecular functions (Figure 3C), such as GO:0015267 (channel activity), GO:0022838 (substrate-specific channel activity), GO:0008509 (anion transmembrane transporter activity), GO:0022839 (ion gated channel activity), GO:0017171 (serine hydrolase activity), GO:0008236 (serine-type peptidase activity), GO:0004252 (serinetype endopeptidase activity), GO:0005237 (inhibitory extracellular ligand-gated ion channel activity).

In a KEGG analysis, these pathways including hsa04080 (Neuroactive ligand-receptor interaction), hsa04727 (GABAergic synapse), hsa05032 (Morphine addiction), hsa04960 (Aldosterone-regulated sodium reabsorption) and hsa04950 (Maturity onset diabetes of the young) pathways associated with CDCA3 function in KIRP (Figure 3D).

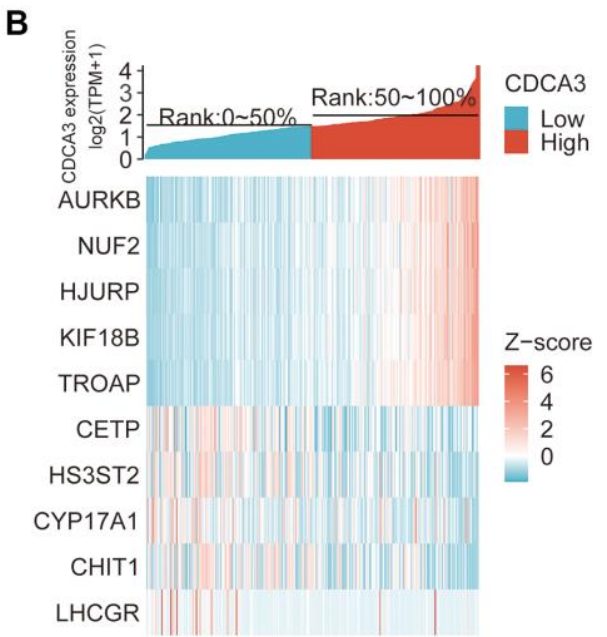

Figure 2. DEGs associated with CDCA3 in KIRP. (A) The results of the DEGs analysis with a volcano graph. $|\operatorname{logFC}|>1.5$ and $p a d j<0.05$. (B) The results of the most distinctly DEGs with a heat map. 


\section{CDCA3-related signaling pathways based on GSEA}

GSEA was used to identify signaling pathways involved in the difference between CDCA3-low expression group and CDCA3-high expression group in KIRP. Figure 4 shows typical results of the GSEA for a single gene set. The reference gene set was h.all.v7.0.symbols.gmt, the selected visualization data sets were HALLMARK_E2 F_TARGETS $($ NES $=1.995, p \cdot \operatorname{adj}=0.013$, FDR $=$ 0.005), HALLMARK_MITOTIC_SPINDLE (NES = $1.726, p \cdot \operatorname{adj}=0.013$, FDR $=0.005)$, HALLMARK_KRA S_SIGNALING_DN $(\mathrm{NES}=1.530, p \cdot \mathrm{adj}=0.013, \mathrm{FDR}=$
0.005), and HALLMARK_G2M_CHECKPOINT (NES = $2.118, p \cdot$ adj $=0.013$, FDR $=0.005)$. The data sets were significantly enriched in CDCA3-high expression group.

\section{Immune cell infiltration}

Spearman correlation analyses were performed to evaluate the associations between the CDCA3 expression and the infiltration of 24 types of immune cells quantified by ssGSEA in KIRP. We investigated whether the CDCA3 mRNA expression level correlated with immune infiltration levels in KIRP. The CDCA3
A
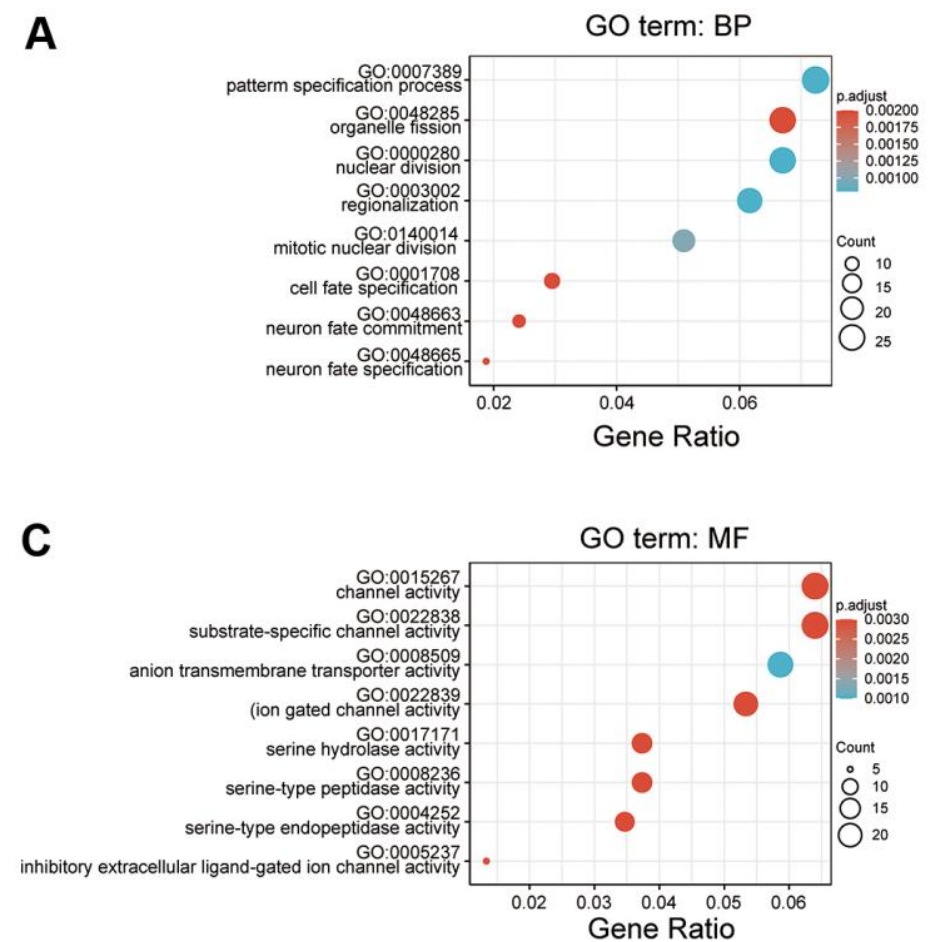

B

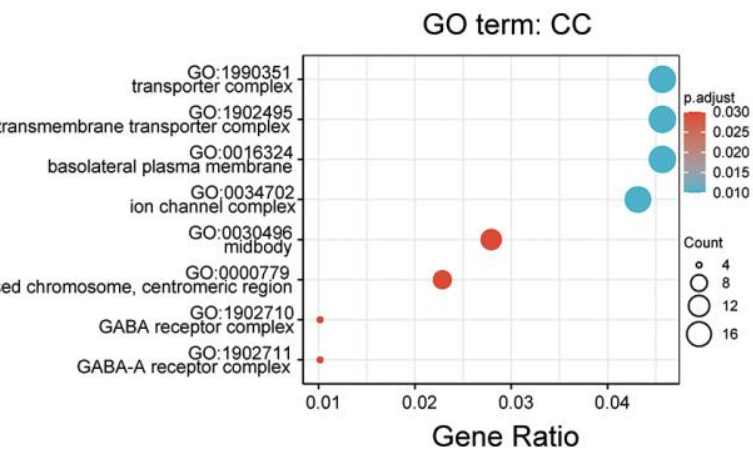

D

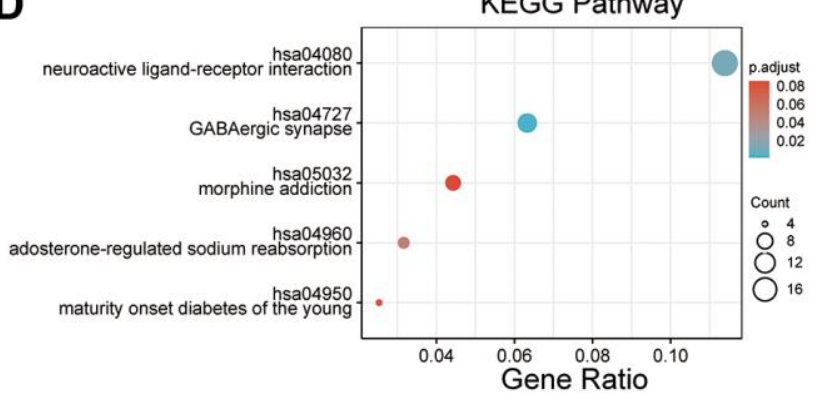

Figure 3. GO and KEGG pathway enrichment analyses. (A-C) GO enrichment analyses of DEGs associated with CDCA3. (A) Cellular component; (B) Biological processes; (C) Molecular functions (D) KEGG enrichment analyses of DEGs associated with CDCA3.
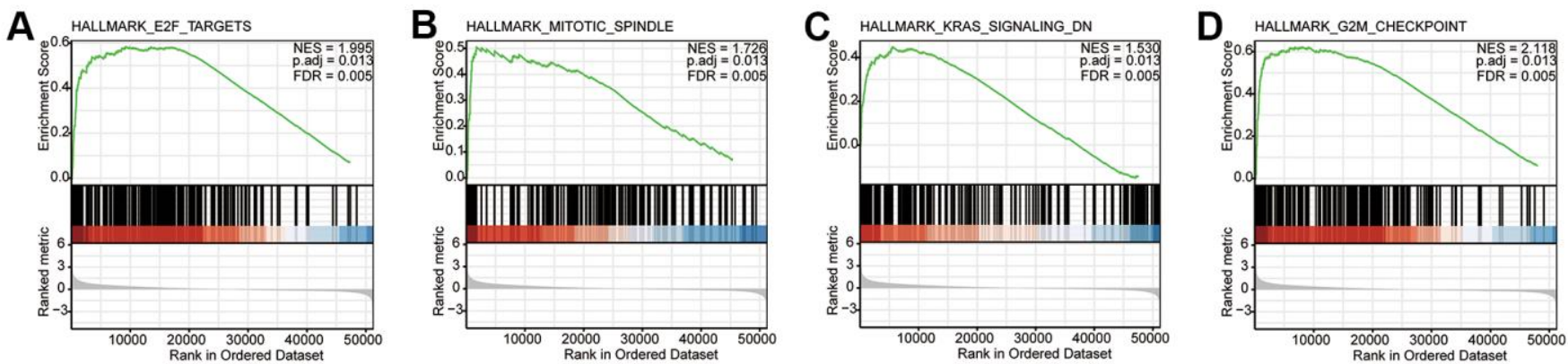

Figure 4. CDCA3-related signaling pathways based on GSEA. (A-D) Typical results of the GSEA for a single gene set. NES, normalized ES; $p$.adj, adjust $p$ value; FDR, false discovery rate. 
mRNA expression obviously related to frequencies of infiltrated iDCs, macrophages, neutrophils, DCs, B cells, Tgd, cytotoxic cells, Th17, $\mathrm{CD}^{+} \mathrm{T}$ cells, $\mathrm{T}$ cells, Tcm, pDCs, $\mathrm{T}$ helper cells and Th2 cells (Figure 5).

\section{PPI network construction}

A PPI network was constructed using Cytoscape (Figure 6A) and the most significant module was selected using MCODE of Cytoscape (Figure 6B).

A
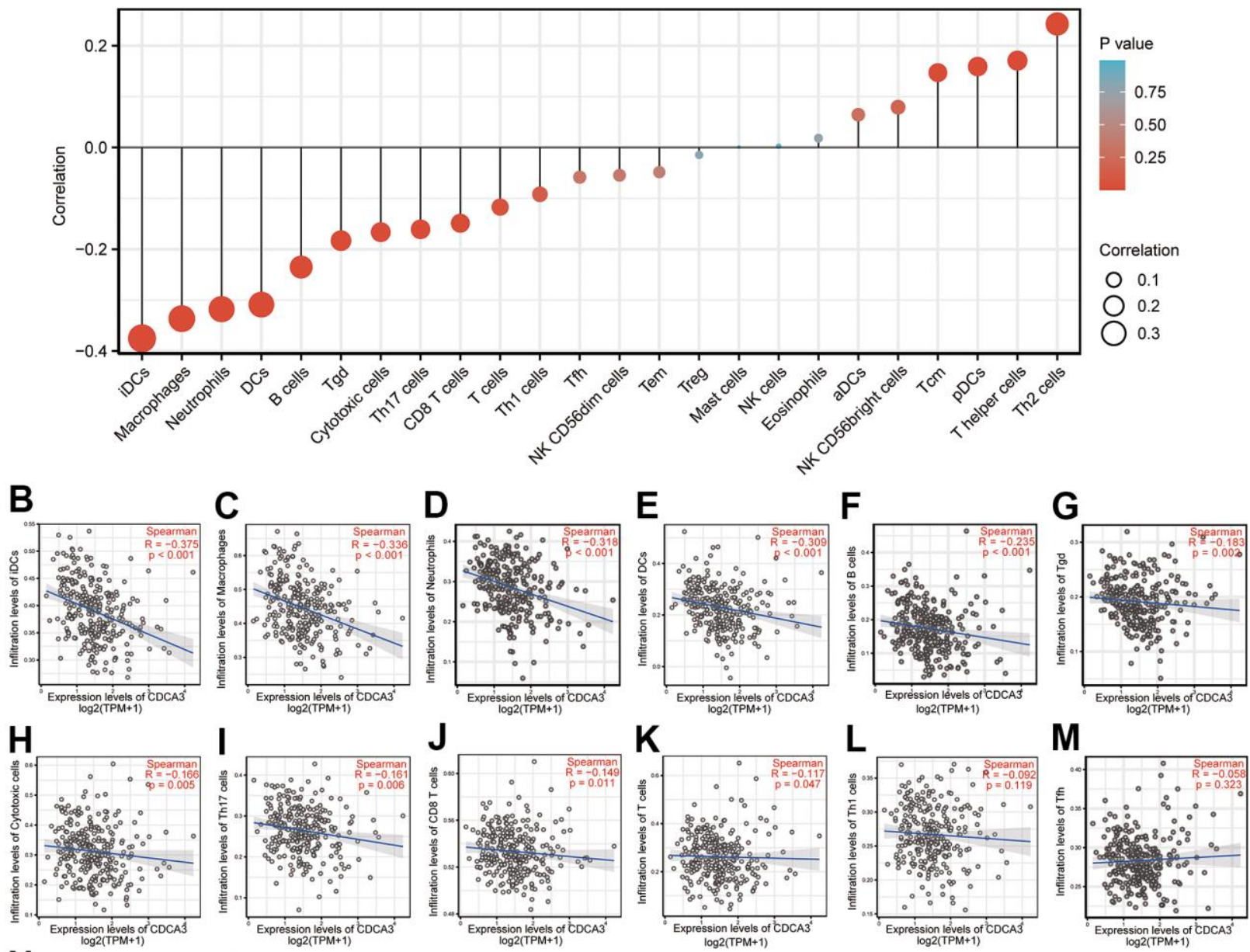

M
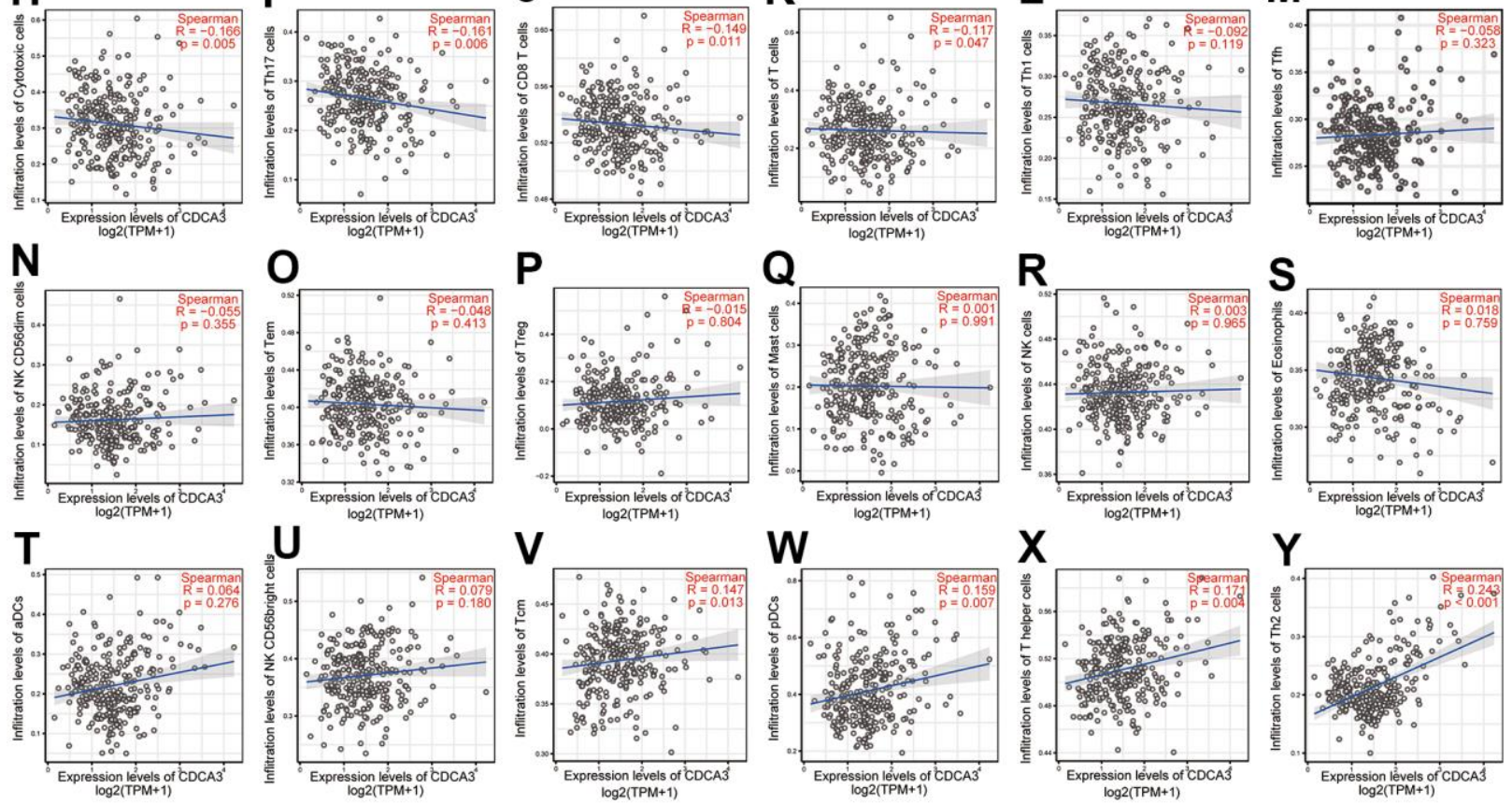

Figure 5. Immune cell infiltration. (A-Y) Spearman correlation analyses of the associations between the CDCA3 expression and the infiltration of 24 types of immune cells. 
The protein with the highest connectivity was identified as CENPF.

\section{Clinicopathological factors associated with $\mathrm{CDCA3}$ in KIRP}

Next, the relationships between the CDCA3 mRNA expression with clinicopathological parameters of KIRP patients with KIRP were analyzed, including clinical stage, gender, race, age, smoking status, serum calcium, hemoglobin, laterality and MET status. As was shown in Figure 7, CDCA3 mRNA expressions levels remarkably associated with the clinical $\mathrm{T}$ stage, clinical $\mathrm{N}$ stage, clinical $\mathrm{M}$ stage, clinical stage, age and hemoglobin. No statistically significant relationships were observed between CDCA3 expression and gender, race, smoking status, serum calcium, laterality and MET. Consistent results were obtained using the chisquare test and Fisher's exact test (Table 1).

Collectively, our results showed that CDCA3 mRNA expression associated with some of the clinicopathological parameters of KIRP.

\section{ROC analysis}

Performing ROC analysis, we determined the diagnostic efficacy of CDCA3 for KIRP. We found that the CDCA3 expression status could serve as a potential predictor for KIRP in both the TCGA database (AUC $=0.888$ ) and the TCGA combined with the GTEX database $(\mathrm{AUC}=0.823)($ Figure $8 \mathrm{~A}, 8 \mathrm{~B})$.

\section{Logistic regression}

The logistic regression method was used to analyze the relationships between clinicopathological characteristics and low or -high CDCA3 expression. CDCA3 expression significantly correlated with the clinical $\mathrm{T}$ stage $(p<0.001)$, clinical N stage $(p=0.003)$, clinical M stage $(p=0.041)$, and Clinical stage $(\mathrm{p}=0.027)$ (Table 2).

\section{Survival analyses}

The Kaplan-Meier curves were generated to evaluate the prognostic value of CDCA3 with respect to the overall survival (OS), progression-free interval (PFI), and disease-specific survival (DSS) in CDCA3 expression subgroups in KIRP. High CDCA3 expression in KIRP associated with a worse OS $(\mathrm{HR}=3.75(1.93-7.31), p<0.001)$ (Figure 9A). Similar results were obtained in PFI analysis $(\mathrm{HR}=4.39(2.38-8.10), p<0.001)$ and DSS analysis $(\mathrm{HR}=15.90(3.77-67.05), p<0.001)$ analyses (Figure 9B, 9C).

A univariate analysis revealed that the clinical $\mathrm{T}$ stage, clinical $\mathrm{N}$ stage, clinical $\mathrm{M}$ stage, clinical stage, hemoglobin and CDCA3 expression were associated with a shorter OS. A multivariate analyses also revealed that the clinical $\mathrm{N}$ stage $(p=0.012)$, clinical $\mathrm{M}$ stage $(p=0.008)$, and CDCA3 expression $(p=0.017)$ were independent factors associated with a poor OS (Table 3 ).

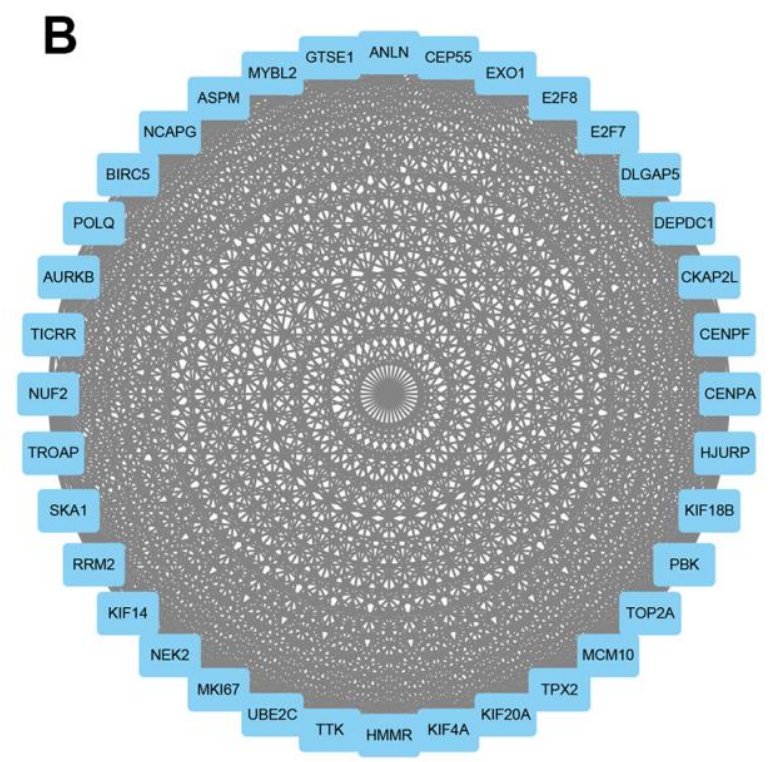

Figure 6. PPI network construction. (A) A PPI network was constructed using Cytoscape. (B) The most significant module was using MCODE of Cytoscape. 
Univariate analyses revealed that the clinical T stage ( $p$ $<0.001)$, clinical N stage $(p<0.001)$, clinical M stage $(p<0.001)$, clinical stage $(p<0.001)$, gender $(p=$ $0.026)$, hemoglobin $(p=0.039)$, and CDCA3 expression $(p<0.001)$ were associated with a worse PFI. A multivariate Cox regression further showed that the clinical $\mathrm{N}$ stage $(p=0.006)$ and CDCA3 expression $(p=$ $0.017)$ were independent prognostic factors based on PFI (Table 4). Similar results were obtained in DSS analysis, indicating that clinical $\mathrm{N}$ stage $(p=0.012)$, clinical M stage $(p=0.008)$, and CDCA3 expression $(p=0.017)$ were independent factors associated with a poorer DSS (Table 5). Calibration curve were developed to evaluate the predictive accuracy of these predictors for OS, PFI, and DSS respectively. The independent predictors could predict the prognosis based on OS (C-index $=0.884(0.857-0.911))$, PFI (Cindex $=0.807(0.773-0.841)$ ), and DSS (C-index = $0.921(0.903-0.940))$.

Finally, we analyzed the prognostic value of CDCA3 expression based on OS, PFI, and DSS in each clinicopathological subgroups of KIRP. As shown in Figure 10, the prognostic value of CDCA3 expression was statistically significant in the following subgroups: $\mathrm{T} 1$ and $\mathrm{T} 2$ for the clinical T stage $(\mathrm{HR}=2.889(1.109$ 7.528), $p=0.030$ ), and the M0 subgroup of the clinical $\mathrm{M}$ stage $(\mathrm{HR}=3.307(1.446-7.563), p=0.005)$, clinical stage II, stage III, and stage IV subgroups of clinical stage $(\mathrm{HR}=10.106(2.326-43.908), p=0.002)$, male
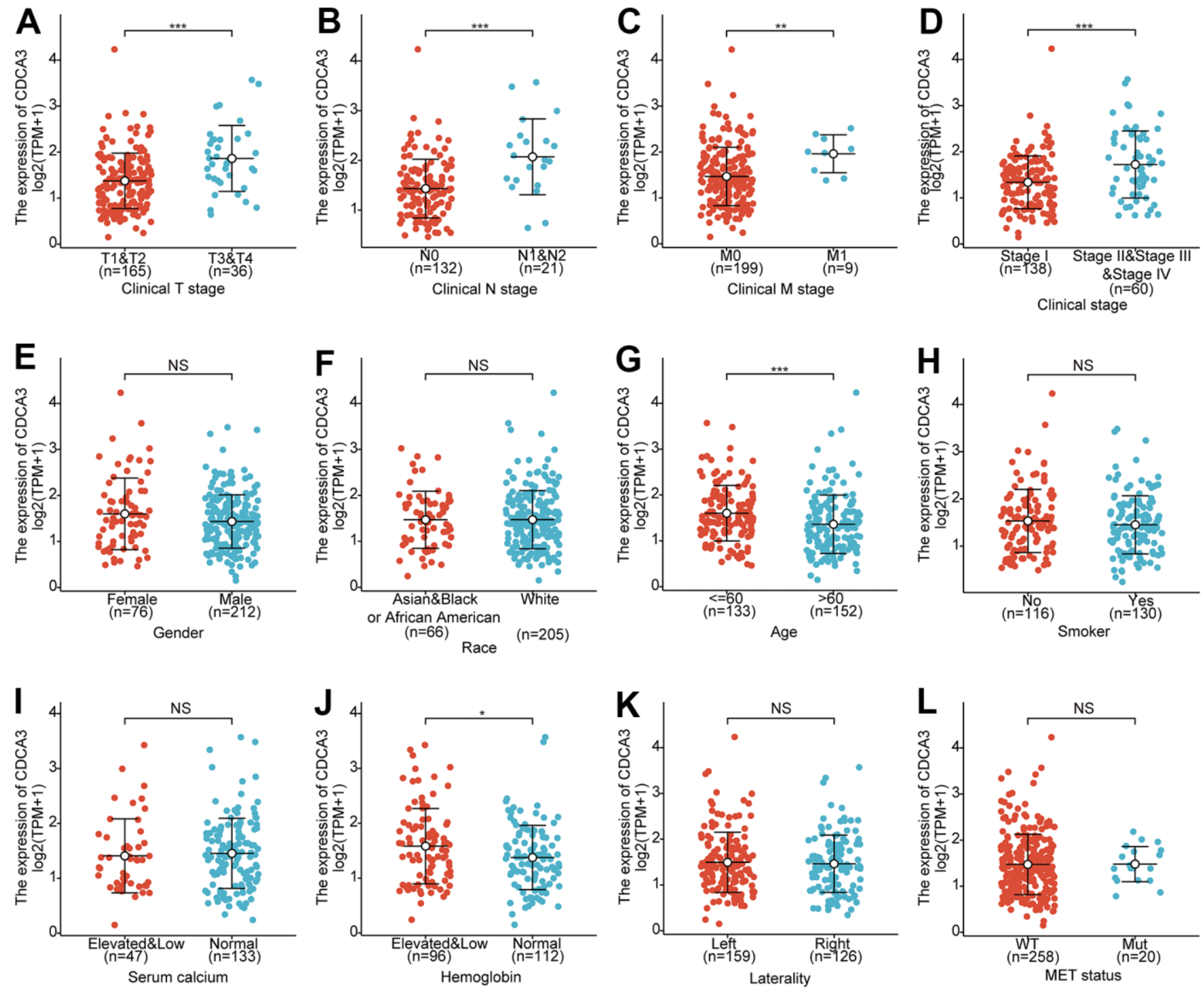

Figure 7. Clinicopathological factors associated with CDCA3 in KIRP. (A-L) CDCA3 mRNA expression with clinicopathological parameters of patients with KIRP, including clinical stage, gender, race, age, smoking status, serum calcium, hemoglobin, laterality and MET status. ns, $p \geq 0.05 ; *, p<0.05 ; * *, p<0.01 ; * * *, p<0.001$. 
Table 1. Clinicopathological factors associated with CDCA3 in KIRP.

\begin{tabular}{|c|c|c|c|c|c|}
\hline Characters & Level & Low expression of CDCA3 & High expression of CDCA3 & $\mathbf{p}$ & Test \\
\hline $\mathrm{n}$ & & 144 & 144 & & \\
\hline \multirow{4}{*}{ Clinical T stage (\%) } & $\mathrm{T} 1$ & $78(75.0 \%)$ & $61(62.9 \%)$ & 0.002 & exact \\
\hline & $\mathrm{T} 2$ & $17(16.3 \%)$ & $9(9.3 \%)$ & & \\
\hline & $\mathrm{T} 3$ & $9(8.7 \%)$ & $26(26.8 \%)$ & & \\
\hline & $\mathrm{T} 4$ & $0(0.0 \%)$ & $1(1.0 \%)$ & & \\
\hline \multirow{3}{*}{ Clinical N stage (\%) } & No & $70(95.9 \%)$ & $62(77.5 \%)$ & 0.001 & exact \\
\hline & N1 & $3(4.1 \%)$ & $16(20.0 \%)$ & & \\
\hline & $\mathrm{N} 2$ & $0(0.0 \%)$ & $2(2.5 \%)$ & & \\
\hline \multirow{2}{*}{ Clinical M stage (\%) } & M0 & $105(99.1 \%)$ & $94(92.2 \%)$ & 0.017 & exact \\
\hline & M1 & $1(0.9 \%)$ & $8(7.8 \%)$ & & \\
\hline \multirow{4}{*}{ Clinical stage $(\%)$} & Stage I & $79(76.7 \%)$ & $59(62.1 \%)$ & $<0.001$ & exact \\
\hline & Stage II & $16(15.5 \%)$ & $5(5.3 \%)$ & & \\
\hline & Stage III & $7(6.8 \%)$ & $22(23.2 \%)$ & & \\
\hline & Stage IV & $1(1.0 \%)$ & $9(9.5 \%)$ & & \\
\hline \multirow{2}{*}{ Smoker $(\%)$} & No & $54(45.0 \%)$ & $62(49.2 \%)$ & 0.525 & exact \\
\hline & Yes & $66(55.0 \%)$ & $64(50.8 \%)$ & & \\
\hline \multirow{2}{*}{ Gender $(\%)$} & Female & $33(22.9 \%)$ & $43(29.9 \%)$ & 0.229 & exact \\
\hline & Male & $111(77.1 \%)$ & $101(70.1 \%)$ & & \\
\hline \multirow{3}{*}{ Race $(\%)$} & Asian & $2(1.5 \%)$ & $4(2.9 \%)$ & 0.830 & exact \\
\hline & $\begin{array}{c}\text { Black or African } \\
\text { American }\end{array}$ & $30(22.2 \%)$ & $30(22.1 \%)$ & & \\
\hline & White & $103(76.3 \%)$ & $102(75.0 \%)$ & & \\
\hline \multirow{3}{*}{ Serum calcium (\%) } & Elevated & $3(3.1 \%)$ & $3(3.6 \%)$ & 0.223 & exact \\
\hline & Low & $27(27.8 \%)$ & $14(16.9 \%)$ & & \\
\hline & Normal & $67(69.1 \%)$ & $66(79.5 \%)$ & & \\
\hline \multirow{3}{*}{ Hemoglobin $(\%)$} & Elevated & $0(0.0 \%)$ & $1(1.0 \%)$ & 0.126 & exact \\
\hline & Low & $44(40.7 \%)$ & $51(51.0 \%)$ & & \\
\hline & Normal & $64(59.3 \%)$ & $48(48.0 \%)$ & & \\
\hline \multirow{2}{*}{ Laterality (\%) } & Left & $80(56.3 \%)$ & $79(55.2 \%)$ & 0.905 & exact \\
\hline & Right & $62(43.7 \%)$ & $64(44.8 \%)$ & & \\
\hline \multirow{2}{*}{ MET status (\%) } & Mut & $10(7.1 \%)$ & $10(7.2 \%)$ & 1.000 & exact \\
\hline & WT & $130(92.9 \%)$ & $128(92.8 \%)$ & & \\
\hline \multirow{2}{*}{ Age $(\%)$} & $<=60$ & $54(37.8 \%)$ & $79(55.6 \%)$ & 0.003 & exact \\
\hline & $>60$ & $89(62.2 \%)$ & $63(44.4 \%)$ & & \\
\hline Age (median [IQR]) & & $64.00[56.50,71.00]$ & $60.00[52.25,67.00]$ & 0.005 & nonnorm \\
\hline
\end{tabular}
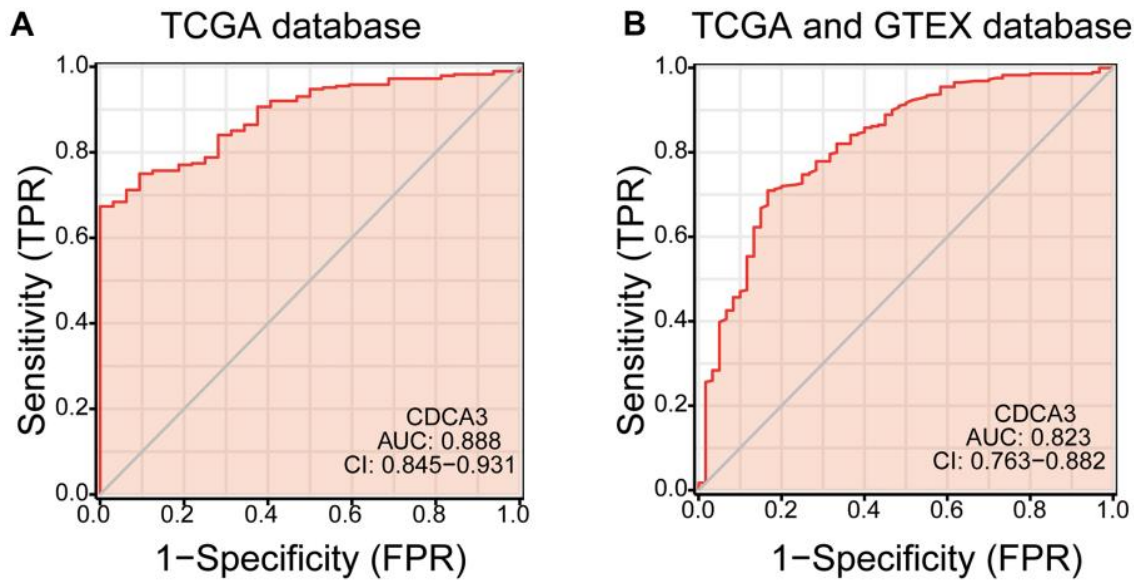

Figure 8. ROC analysis. (A, B) the diagnostic efficacy of CDCA3 for KIRP both the TCGA database and the TCGA combined with the GTEX database. 
Table 2. The relationships between clinicopathological characteristics and low or -high CDCA3 expression.

\begin{tabular}{lccc}
\hline Characteristics & Odds ratio in CDCA3 expression & Odds ratio(OR) & P value \\
\hline Clinical T stage (T3\&T4 vs. T1\&T2) & 201 & $4.07(1.86-9.67)$ & $<0.001$ \\
Clinical N stage (N1\&N2 vs. N0) & 153 & $6.77(2.16-29.90)$ & 0.003 \\
Clinical M stage (M1 vs. M0) & 208 & $8.94(1.60-167.33)$ & 0.041 \\
Clinical stage (Stage II\&Stage III\&Stage IV vs. Stage I) & 198 & $2.01(1.09-3.76)$ & 0.027 \\
Serum calcium (Elevated\&Low vs. Normal) & 180 & $0.58(0.29-1.13)$ & 0.114 \\
Hemoglobin (Elevated\&Low vs. Normal) & 208 & $1.58(0.91-2.74)$ & 0.104 \\
Laterality (Right vs. Left) & 285 & $1.05(0.65-1.67)$ & 0.853 \\
MET status (Mut vs. WT) & 278 & $1.02(0.40-2.56)$ & 0.973 \\
\hline
\end{tabular}
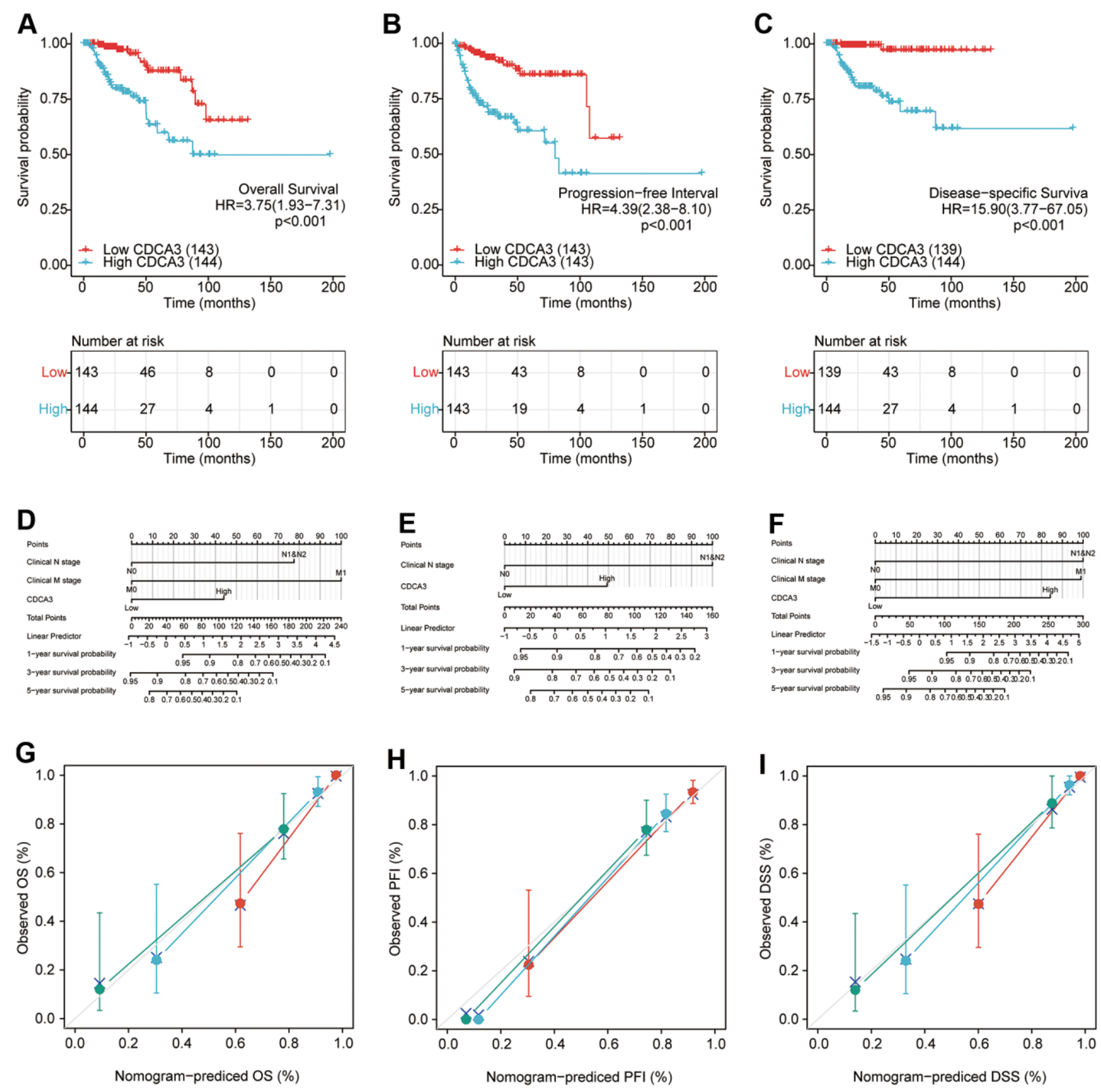

Figure 9. Survival analyses. (A-C)The prognostic value of CDCA3 with OS, PFI, DSS. (D-F) The nomogram of CDCA3 with OS, PFI, DSS. (G-I) The calibration curve of $\mathrm{N}$ stage (green), M stage (blue) and CDCA3 (red) with OS, PFI, DSS. 
Table 3. A univariate analysis and a multivariate analysis of OS.

\begin{tabular}{|c|c|c|c|c|c|}
\hline Characteristics & Total(N) & $\begin{array}{c}\mathrm{HR}(95 \% \mathrm{CI}) \\
\text { univariate analysis }\end{array}$ & $\begin{array}{c}\text { P value } \\
\text { univariate analysis }\end{array}$ & $\begin{array}{c}\mathrm{HR}(95 \% \mathrm{CI}) \\
\text { multivariate analysis }\end{array}$ & $\begin{array}{c}\text { P value } \\
\text { multivariate analysis }\end{array}$ \\
\hline $\begin{array}{l}\text { Clinical T stage } \\
\text { (T3\&T4 vs. T1\&T2) }\end{array}$ & 201 & $4.687(2.292-9.587)$ & $<0.001$ & $0.517(0.103-2.610)$ & 0.425 \\
\hline $\begin{array}{l}\text { Clinical N stage } \\
(\mathrm{N} 1 \& \mathrm{~N} 2 \text { vs. N0) }\end{array}$ & 153 & $10.637(4.972-22.755)$ & $<0.001$ & $8.218(1.595-42.346)$ & 0.012 \\
\hline $\begin{array}{l}\text { Clinical M stage } \\
\text { (M1 vs. M0) }\end{array}$ & 208 & $38.111(12.616-115.123)$ & $<0.001$ & $12.406(1.931-79.714)$ & 0.008 \\
\hline $\begin{array}{l}\text { Clinical stage } \\
\text { (Stage II\&III\&IV vs.Stage } \\
\text { I) }\end{array}$ & 198 & $5.123(2.450-10.712)$ & $<0.001$ & $4.545(0.856-24.144)$ & 0.076 \\
\hline $\begin{array}{l}\text { Smoker } \\
\text { (Yes vs. No) }\end{array}$ & 245 & $0.564(0.298-1.069)$ & 0.079 & $0.319(0.096-1.055)$ & 0.061 \\
\hline Age $(>60$ vs. $<=60)$ & 285 & $0.956(0.525-1.738)$ & 0.882 & & \\
\hline $\begin{array}{l}\text { Gender } \\
\text { (Male vs. Female) }\end{array}$ & 287 & $0.617(0.320-1.189)$ & 0.149 & & \\
\hline $\begin{array}{l}\text { Race } \\
\text { (White vs. } \\
\text { Asian\&Black or African } \\
\text { American) }\end{array}$ & 271 & $0.921(0.424-2.000)$ & 0.834 & & \\
\hline $\begin{array}{l}\text { Serum calcium } \\
\text { (Elevated\&Low vs. } \\
\text { Normal) }\end{array}$ & 180 & $1.659(0.752-3.661)$ & 0.21 & & \\
\hline $\begin{array}{l}\text { Hemoglobin } \\
\text { (Elevated\&Low vs. } \\
\text { Normal) }\end{array}$ & 208 & $4.381(1.877-10.223)$ & $<0.001$ & $1.958(0.589-6.502)$ & 0.273 \\
\hline $\begin{array}{l}\text { Laterality } \\
\text { (Right vs. Left) }\end{array}$ & 284 & $0.726(0.388-1.359)$ & 0.317 & & \\
\hline $\begin{array}{l}\text { MET status } \\
\text { (Mut vs. WT) }\end{array}$ & 277 & $1.025(0.315-3.336)$ & 0.967 & & \\
\hline $\begin{array}{l}\text { CDCA3 } \\
\text { (High vs. Low) }\end{array}$ & 287 & $3.751(1.926-7.306)$ & $<0.001$ & $5.264(1.354-20.462)$ & 0.017 \\
\hline
\end{tabular}

subgroup $(H R=3.189(1.494-6.807), p=0.003)$, female subgroup $(\mathrm{HR}=5.959(1.315-26.995), p=0.021)$, white subgroup of race $(\mathrm{HR}=3.684(1.759-7.717), p<0.001)$, age less than 60 years old subgroup $(\mathrm{HR}=14.831(1.979$ $111.161), p=0.009$ ), age over 60 years old subgroup (HR $=3.176(1.413-7.138), p=0.005)$, non-smoking subgroup $(\mathrm{HR}=4.250 \quad(1.426-12.664), p=0.009)$, smoking subgroup $(\mathrm{HR}=3.173(1.155-8.715), p=0.025)$, normal serum calcium subgroup $(\mathrm{HR}=6.427(1.775-23.269), p=$ 0.005), elevated and low hemoglobin subgroup ( $\mathrm{HR}=$ 4.488(1.735-11.607), $p=0.002)$, left laterality subgroup $(\mathrm{HR}=4.132(1.813-9.421), p<0.001)$, and wild type subgroup $(\mathrm{HR}=3.536(1.746-7.160), p<0.001)$. The analyses of the prognostic value of CDCA3 expression in each KIRP subgroup based on PFI and DSS also yielded similar results.

\section{DISCUSSION}

KIRP accounts for approximately 10-20\% of RCC cases. KIRP tends to occur in individuals over 50 years of age and affects more men than women, with a genetic predisposition. KIRP is typically discovered incidentally during physical examination. Some patients have typical clinical manifestations of RCC, such as hematuria, lumbago, and abdominal masses. The pathological features of KIRP are solid tumors in the renal cortex with clear boundaries. [8]. The prognosis of KIRP is better than that of KIRC, however, it is closely related to tumor stage or grade [27]. Compared with KIRC, KIRP grows slowly and is often enveloped. Distant metastasis and the infiltration of surrounding tissue are relatively rare. Most KIRP tumors have a low TNM stage.

Several cytokines, hormones, and proteins are involved in the development and progression of RCC and KIRP. Galectin-3 is widely expressed in RCC, and promotes the invasiveness, and suggestiveness via CXCR2, thereby affecting the occurrence and development of RCC [28]. Activation of p53 and HIF-1 $\alpha$ promoted the transformation of RCC cells [29]. Peckova et al. found that most KIRP cells exhibit polysomy of chromosome 17 and chromosome 7 and expressed AMACR, OSCAR, CAM 5.2, HIF-2, and vimentin [30]. However, some type I KIRPs were accompanied by 
Table 4. A univariate analysis and a multivariate analysis of PFI.

\begin{tabular}{|c|c|c|c|c|c|}
\hline Characteristics & Total(N) & $\begin{array}{c}\mathrm{HR}(95 \% \mathrm{CI}) \\
\text { univariate analysis }\end{array}$ & $\begin{array}{c}\text { P value } \\
\text { univariate analysis }\end{array}$ & $\begin{array}{c}\mathrm{HR}(95 \% \mathrm{CI}) \\
\text { multivariate analysis }\end{array}$ & $\begin{array}{c}\text { P value } \\
\text { multivariate analysis } \\
\end{array}$ \\
\hline $\begin{array}{l}\text { Clinical T stage } \\
\text { (T3\&T4 vs. T1\&T2) }\end{array}$ & 200 & 7.383(3.906-13.955) & $<0.001$ & $1.565(0.420-5.825)$ & 0.504 \\
\hline $\begin{array}{l}\text { Clinical N stage } \\
\text { (N1\&N2 vs. N0) }\end{array}$ & 152 & $17.022(8.265-35.057)$ & $<0.001$ & 7.079(1.774-28.254) & 0.006 \\
\hline $\begin{array}{l}\text { Clinical M stage } \\
\text { (M1 vs. M0) }\end{array}$ & 207 & $10.324(4.129-25.818)$ & $<0.001$ & $0.829(0.167-4.123)$ & 0.819 \\
\hline $\begin{array}{l}\text { Clinical stage } \\
\text { (Stage II\&III\&IV vs. Stage } \\
\text { I) }\end{array}$ & 197 & $6.983(3.557-13.708)$ & $<0.001$ & $2.124(0.596-7.569)$ & 0.245 \\
\hline $\begin{array}{l}\text { Smoker } \\
\text { (Yes vs. No) }\end{array}$ & 244 & $1.230(0.708-2.139)$ & 0.463 & & \\
\hline $\begin{array}{l}\text { Age } \\
(>60 \text { vs. }<=60)\end{array}$ & 284 & $0.820(0.483-1.391)$ & 0.461 & & \\
\hline $\begin{array}{l}\text { Gender } \\
\text { (Male vs. Female) }\end{array}$ & 286 & $0.528(0.301-0.925)$ & 0.026 & $2.035(0.591-7.009)$ & 0.26 \\
\hline $\begin{array}{l}\text { Race } \\
\text { (White vs. } \\
\text { Asian\&Black or African } \\
\text { American) }\end{array}$ & 270 & $0.863(0.451-1.651)$ & 0.657 & & \\
\hline $\begin{array}{l}\text { Serum calcium } \\
\text { (Elevated\&Low vs. Normal) }\end{array}$ & 179 & $1.180(0.542-2.565)$ & 0.677 & & \\
\hline $\begin{array}{l}\text { Hemoglobin } \\
\text { (Elevated\&Low vs. Normal) }\end{array}$ & 207 & $1.976(1.035-3.772)$ & 0.039 & $2.038(0.799-5.203)$ & 0.136 \\
\hline $\begin{array}{l}\text { Laterality } \\
\text { (Right vs. Left) }\end{array}$ & 283 & $0.770(0.443-1.339)$ & 0.355 & & \\
\hline $\begin{array}{l}\text { MET status } \\
\text { (Mut vs. WT) }\end{array}$ & 276 & $1.158(0.416-3.221)$ & 0.779 & & \\
\hline $\begin{array}{l}\text { CDCA3 } \\
\text { (High vs. Low) }\end{array}$ & 286 & $4.388(2.376-8.105)$ & $<0.001$ & $3.293(1.241-8.740)$ & 0.017 \\
\hline
\end{tabular}

abnormalities of chromosomes 3, 12, 16, and 20 [31]. Mutations associated with KIRP, including MET mutations and mutations resulting in chromatin modifications, have been reported [5]. MET inhibitors could effectively improve the prognosis of metastatic KIRP $[32,33]$. EpCAM has prognostic value in KIRP, and the overexpression of EpCAM in high-grade KIRP could be a useful indicator of prognosis [34]. However, compared with metastatic KIRP, TKI, and mTOR inhibitors are less effective in KIRP, with lower 5-year survival rates [35].

CDCA3, as a part of the skp1-cullin-f-box ubiquitin ligase complex, regulates the cell cycle by acting as an endogenous cell cycle inhibitor. CDCA3 participates in human physiological and pathological processes via regulating various downstream cytokines, hormones, and proteins. As shown in Figure 1A-1B, the expression of CDCA3 was up-regulated in a variety of tumor tissues. Several other studies have also shown that CDCA3 plays a significant role in the occurrence and development of tumors, including non-small cell lung cancer, prostate cancer, breast cancer, and KIRC [17]. The expression of CDCA3 in non-small cell lung cancer cells is significantly increased, and is closely related to a poor prognosis [18]. CDCA3 overexperssion promotes the proliferation of colorectal cancer cells, while knocking down CDCA3 expression in vivo and in vitro decreases the proliferation of colorectal cancer cells [36]. In particular, the inhibition of CDCA3 expression induces cell cycle arrest in colorectal cancer cells, thereby promoting cell apoptosis [37]. CDCA3 expression is increased in gastric cancer cells and is associated with a poor prognosis. CDCA3 overexpression in vivo and in vitro promotes the growth and colony formation ability of gastric cancer cells, while inhibiting CDCA3 expression mitigates these effects [38]. Furthermore, in gastric cancer CDCA3 expression is regulated by DNA methylation, and the binding activity of SP1 and the CDCA3 promoter is significantly up-regulated. Knockdown of SP1 downregulated CDCA3 expression, and the proliferation and invasion of gastric cancer cells is significantly inhibited [39]. In leukemia cell lines, miR375 expression is down-regulated, and miR-375 inhibits CDCA3 expression by downregulating HOXB3 expression, thereby suppressing cell proliferation [38]. CDCA3 is overexpressed in bladder cancer and is 
Table 5. A univariate analysis and a multivariate analysis of DSS.

\begin{tabular}{|c|c|c|c|c|c|}
\hline Characteristics & Total(N) & $\begin{array}{c}\mathrm{HR}(95 \% \mathrm{CI}) \\
\text { univariate analysis }\end{array}$ & $\begin{array}{c}\text { P value } \\
\text { univariate analysis }\end{array}$ & $\begin{array}{c}\mathrm{HR}(95 \% \mathrm{CI}) \\
\text { multivariate analysis }\end{array}$ & $\begin{array}{c}\text { P value } \\
\text { multivariate analysis } \\
\end{array}$ \\
\hline $\begin{array}{l}\text { Clinical T stage } \\
\text { (T3\&T4 vs. T1\&T2) }\end{array}$ & 200 & $8.926(3.806-20.932)$ & $<0.001$ & $0.428(0.077-2.375)$ & 0.331 \\
\hline $\begin{array}{l}\text { Clinical N stage } \\
(\mathrm{N} 1 \& \mathrm{~N} 2 \text { vs. N0) }\end{array}$ & 153 & $19.162(7.687-47.767)$ & $<0.001$ & 7.003(1.299-37.743) & 0.024 \\
\hline $\begin{array}{l}\text { Clinical M stage } \\
\text { (M1 vs. M0) }\end{array}$ & 207 & $40.575(13.073-125.940)$ & $<0.001$ & $11.825(1.548-90.309)$ & 0.017 \\
\hline $\begin{array}{l}\text { Clinical stage } \\
\text { (Stage II\&III\&IV vs. Stage I) }\end{array}$ & 197 & $27.918(6.516-119.621)$ & $<0.001$ & $10.927(0.945-126.326)$ & 0.056 \\
\hline $\begin{array}{l}\text { Smoker } \\
\text { (Yes vs. No) }\end{array}$ & 242 & $0.610(0.284-1.310)$ & 0.205 & & \\
\hline $\begin{array}{l}\text { Age } \\
(>60 \text { vs. }<=60)\end{array}$ & 281 & $0.447(0.206-0.969)$ & 0.041 & $1.425(0.359-5.659)$ & 0.615 \\
\hline $\begin{array}{l}\text { Gender } \\
\text { (Male vs. Female) }\end{array}$ & 283 & $0.544(0.250-1.180)$ & 0.123 & & \\
\hline $\begin{array}{l}\text { Race } \\
\text { (White vs. } \\
\text { Asian\&Black or African } \\
\text { American) }\end{array}$ & 267 & $0.891(0.358-2.220)$ & 0.805 & & \\
\hline $\begin{array}{l}\text { Serum calcium } \\
\text { (Elevated\&Low vs. Normal) }\end{array}$ & 177 & $1.749(0.633-4.833)$ & 0.281 & & \\
\hline $\begin{array}{l}\text { Hemoglobin } \\
\text { (Elevated\&Low vs. Normal) }\end{array}$ & 205 & $3.174(1.204-8.368)$ & 0.02 & $1.760(0.414-7.479)$ & 0.444 \\
\hline $\begin{array}{l}\text { Laterality } \\
\text { (Right vs. Left) }\end{array}$ & 280 & $0.508(0.223-1.155)$ & 0.106 & & \\
\hline $\begin{array}{l}\text { MET status } \\
\text { (Mut vs. WT) }\end{array}$ & 273 & $0.508(0.069-3.754)$ & 0.507 & & \\
\hline $\begin{array}{l}\text { CDCA3 } \\
\text { (High vs. Low) }\end{array}$ & 283 & $15.895(3.768-67.047)$ & $<0.001$ & $5.264(1.093-25.343)$ & 0.038 \\
\hline
\end{tabular}

related to prognosis [40] and its high expression is closely related to survival in breast cancer [41].

The prognosis value of CDCA3 in KIRP remains unclear and was the focus of this study. We observed that CDCA3 in KIRP tissues was significantly upregulated compared to level in normal or paired paracancerous normal tissues (Figure 1C, 1D). Our results showed that compared to the levels in normal samples, CDCA3 mRNA expression in KIRP samples
A

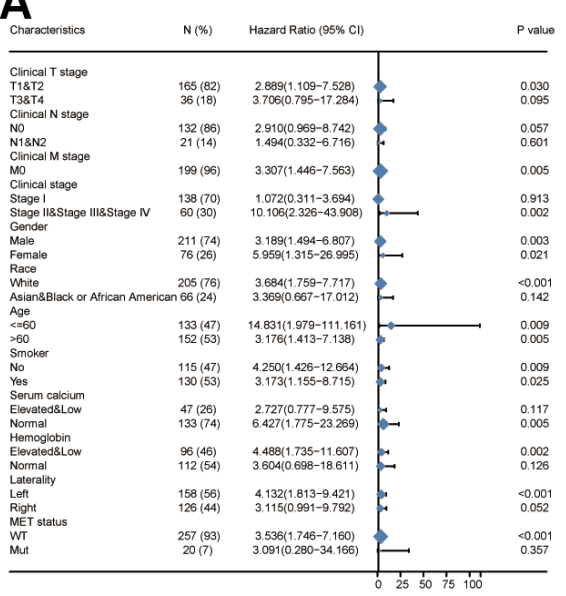

B

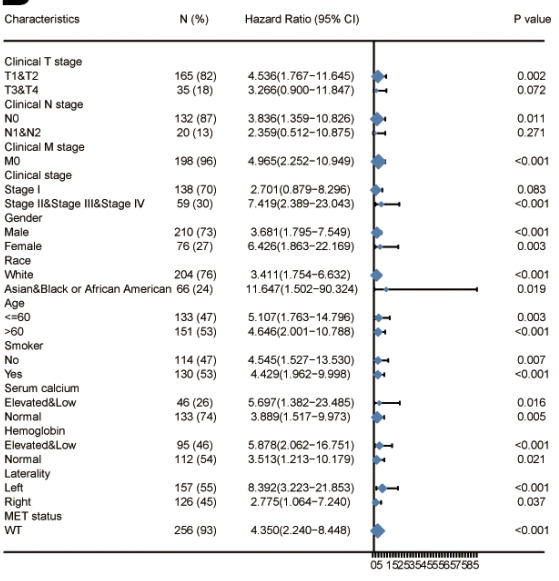

C

\begin{tabular}{|c|c|c|c|c|}
\hline Characteristics & $N(\%)$ & Hazard Ratio (95\% CI) & & $P$ value \\
\hline $\begin{array}{l}\text { Clinical T stage } \\
\text { T3\&T4 }\end{array}$ & $36(18)$ & $3.706(0.795-17.284)$ & 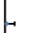 & 0.095 \\
\hline $\begin{array}{l}\text { Clilical N stage } \\
\text { N18N2 }\end{array}$ & 21 (14) & $1.494(0.332-6.716)$ & 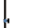 & 0.001 \\
\hline $\begin{array}{l}\text { Clinical M stage } \\
\text { Mo }\end{array}$ & $198(96)$ & $10.855\{2.493-47.269\}$ & _ & 0.001 \\
\hline $\begin{array}{l}\text { Clinica stateg } \\
\text { Stage IISSiage IIISSiage IV }\end{array}$ & $60(30)$ & $10.106(2.326-43.908)$ & $\ldots$ & 0.002 \\
\hline $\begin{array}{l}\begin{array}{l}\text { Gender } \\
\text { Male }\end{array} \\
\text {. }\end{array}$ & $207(73)$ & $10.145(2.326-44.250)$ & $\rightarrow$ & 0.002 \\
\hline $\begin{array}{l}\text { Race } \\
\text { White }\end{array}$ & $201(75)$ & $11.7200(2.726-50.390)$ & 0 & $<0.001$ \\
\hline 年9 & $148(53)$ & $6.951(1.468-32.902)$ & . & 0.015 \\
\hline $\begin{array}{l}\text { Smoker } \\
\text { No }\end{array}$ & $115(48)$ & $6.618(1.491-29.370)$ & r & 0.013 \\
\hline $\begin{array}{l}\text { Serum acalcium } \\
\text { Elevartedslow } \\
\text { Normal }\end{array}$ & $\begin{array}{l}45(25) \\
132(75)\end{array}$ & $\begin{array}{l}\begin{array}{l}10.227(1.190-87.998) \\
11.282(1.428-89.135)\end{array}\end{array}$ & & $\begin{array}{l}0.034 \\
0.022\end{array}$ \\
\hline 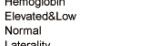 & $\begin{array}{l}93(45) \\
112(55)\end{array}$ & $\begin{array}{l}14.388(1.850-111.916) \\
7.134(1.0 .832-61.175)\end{array}$ & - & $\begin{array}{l}0.011 \\
0.073\end{array}$ \\
\hline 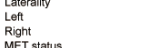 & $\begin{array}{l}155(55) \\
125(45)\end{array}$ & $\begin{array}{l}24.372(3.257-182.394) \\
7.774(0.055-63.3931)\end{array}$ & - & $\begin{array}{l}0.002 \\
0.055\end{array}$ \\
\hline $\begin{array}{l}\text { MET siatus } \\
\text { WT }\end{array}$ & $254(93)$ & $14.360(3.3800-61.019\}$ & 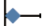 & $<0.001$ \\
\hline
\end{tabular}

Figure 10. Survival analysis of subgroups. (A-C) Prognostic value of CDCA3 with OS, PFI, DSS of KIRP subgroup. 
was significantly up-regulated based on the KIRP data from TCGA and the GTEx database. Moreover, 739 DEGs were identified between groups with low and high \# expression. As shown in Figure 3A, CDCA3 and its related DEGs are involved several diverse biological processes, such as nuclear division and mitotic nuclear division. Qiu [42] reported that CDCA3 is involved in cell mitosis, validating our results. A GSEA indicated that CDCA3 is related to various gene sets, such as E2F targets, spindle formation during mitosis, KRAS signaling, and G2M checkpoints (Figure 4). E2F4 promotes proliferation and cell cycle progression in hepatocellular carcinoma cells by up-regulating CDCA3 expression [43]. Numerous studies have shown that CDCA3 is related to cell mitosis $[36,42]$. These results confirmed the results of the GSEA in present study. We found that the infiltration of various immune cells was notably related to CDCA3 mRNA expression (Figure 5). Based on the TIMER database, Wang [44] found that CDCA3 is related to the infiltration of many immune cells in hepatocellular carcinoma. Immune cell infiltration is gaining increasing attention in tumor biology research, however, relatively few studies have explored the relationship between CDCA3 and immune cell infiltration. In our study, the PPI network was constructed by Cytoscape and the most significant module was selected by MCODE of Cytoscape (Figure 6). The highest connectivity was screened as CENPF, CENPA, KIF4A, UBE2C among others.

Studies have shown that the expression levels of CDCA3 and CENPF are correlated in esophageal carcinoma [45]. Levels of CDCA3, CENPF, CENPA and KIF4A are correlated in bladder cancer [40]. Our result showed that CDCA3 mRNA expressions remarkably correlated with the clinical $\mathrm{T}$ stage, clinical N stage, clinical M stage, clinical stage, age, and hemoglobin. Furthermore, the CDCA3 expression status had high diagnostic value in KIRP. Moreover, in a logistic regression analysis, CDCA3 was significantly correlated with clinical $\mathrm{T}$ stage, clinical $\mathrm{N}$ stage, clinical $M$ stage, and clinical stage. High CDCA3 expression in KIRP was associated with a worse OS, PFI and DSS. Besides, univariate and multivariate analyses supported the prognostic value of CDCA3 based on OS, PFI and DSS in various subgroups of KIRP.

Despite presenting some credible data and experimental evidence, this study has some limitations. First, all the data were obtained from online databases and only in silico analyses were performed, further in vivo and in vitro studies are required to verify our results. Second, we found that
CDCA3 was related to KIRP and could be used as a potential predictor of the prognosis. However, the underlying mechanisms by which CDCA3 regulates the occurrence and development of KIRP remains unclear. Further research studies to reveal the detailed mechanism underlying the relationship between CDCA3 and KIRP.

In conclusion, our results showed that $\mathrm{CDCA} 3$ is overexpressed in KIRP. The infiltration of various immune cells was notably related to CDCA3 mRNA expressions. Moreover, CDCA3 was significantly associated with the clinical $\mathrm{T}$ stage, clinical $\mathrm{N}$ stage, clinical $\mathrm{M}$ stage, clinical stage, age and hemoglobin in KIRP. Furthermore, high expression level of CDCA3 were significantly related to a shorter OS, PFI, and DSS in KIRP. Accordingly, CDCA3 is a potential target for the development of anti-KIRP therapeutics and an efficient prognostic marker for KIRP.

\section{Abbreviations}

RCC: Renal cell carcinoma; KIRP: Kidney renal papillary cell carcinoma, also known as papillary renal cell carcinoma (PRCC); CT: computed tomography; MRI: computed tomography; CDCA3: Cell division cycle associated 3; TCGA: The Cancer Genome Atlas; GO: Gene Ontology; DEGs: differential expression genes; GSEA: gene set enrichment analysis; PPI: protein-protein interaction; FPKM: fragments per kilobase per million; TPM: transcripts per million reads; KEGG: Kyoto Encyclopedia of Genes and Genomes; DCs: dendritic cells (DCs); aDCs: activated DCs (aDCs); pDCs: plasmacytoid DCs; iDCs: immature DCs; Th: T helper cells (Th); Treg: Regulatory T cells (Treg); Tgd: T gamma delta; Tcm: T central memory; Tem: $\mathrm{T}$ effector memory; Tfh: $\mathrm{T}$ follicular helper; MCODE: Molecular Complex Detection); ROC: Receiver Operating Characteristic; AUC: area under the curve; FPR: False Positive Rate; TPR: True Positive Rate; OS: overall survival; PFI: progression-free interval; DSS: disease-specific survival.

\section{AUTHOR CONTRIBUTIONS}

Xiaojuan Li and Hao Li designed the project, selected the analyzed results, and wrote the paper. Mi Li and Sisi Deng suggested online tools. All authors contributed to the article and approved the submitted version.

\section{CONFLICTS OF INTEREST}

The authors declare that the research was conducted in the absence of any commercial or financial relationships that could be construed as a potential conflict of interest. 


\section{FUNDING}

The present study was supported by the National Natural Science Foundation of China (Grant No. 81874020).

\section{REFERENCES}

1. Siegel RL, Miller KD, Jemal A. Cancer statistics, 2020. CA Cancer J Clin. 2020; 70:7-30. https://doi.org/10.3322/caac.21590 PMID:31912902

2. Little RA, Jamin Y, Boult JK, Naish JH, Watson Y, Cheung S, Holliday KF, Lu H, McHugh DJ, Irlam J, West CM, Betts GN, Ashton G, et al. Mapping Hypoxia in Renal Carcinoma with Oxygen-enhanced MRI: Comparison with Intrinsic Susceptibility MRI and Pathology. Radiology. 2018; 288:739-47.

https://doi.org/10.1148/radiol.2018171531 PMID:29869970

3. Armstrong AJ, Halabi $\mathrm{S}$, Eisen $\mathrm{T}$, Broderick $\mathrm{S}$, Stadler WM, Jones RJ, Garcia JA, Vaishampayan UN, Picus J, Hawkins RE, Hainsworth JD, Kollmannsberger CK, Logan TF, et al. Everolimus versus sunitinib for patients with metastatic non-clear cell renal cell carcinoma (ASPEN): a multicentre, open-label, randomised phase 2 trial. Lancet Oncol. 2016; 17:378-88.

https://doi.org/10.1016/S1470-2045(15)00515-X PMID:26794930

4. Tannir NM, Jonasch E, Albiges L, Altinmakas E, Ng CS, Matin SF, Wang X, Qiao W, Dubauskas Lim Z, Tamboli P, Rao P, Sircar K, Karam JA, et al. Everolimus Versus Sunitinib Prospective Evaluation in Metastatic NonClear Cell Renal Cell Carcinoma (ESPN): A Randomized Multicenter Phase 2 Trial. Eur Urol. 2016; 69:866-74. https://doi.org/10.1016/i.eururo.2015.10.049 PMID:26626617

5. Linehan WM, Spellman PT, Ricketts CJ, Creighton CJ, Fei SS, Davis C, Wheeler DA, Murray BA, Schmidt L, Vocke CD, Peto M, Al Mamun AA, Shinbrot E, et al, and Cancer Genome Atlas Research Network. Comprehensive Molecular Characterization of Papillary Renal-Cell Carcinoma. N Engl J Med. 2016; 374:135-45. https://doi.org/10.1056/NEJMoa1505917 PMID:26536169

6. Courthod G, Tucci M, Di Maio M, Scagliotti GV. Papillary renal cell carcinoma: A review of the current therapeutic landscape. Crit Rev Oncol Hematol. 2015; 96:100-12.

https://doi.org/10.1016/i.critrevonc.2015.05.008 PMID:26052049

7. Prasad SR, Humphrey PA, Catena JR, Narra VR, Srigley JR, Cortez AD, Dalrymple NC, Chintapalli KN. Common and uncommon histologic subtypes of renal cell carcinoma: imaging spectrum with pathologic correlation. Radiographics. 2006; 26:1795-806.

https://doi.org/10.1148/rg.266065010

PMID:17102051

8. Amin $M B, A$ min $M B$, Tamboli $P$, Javidan J, Stricker $H$, de-Peralta Venturina $M$, Deshpande $A$, Menon $M$. Prognostic impact of histologic subtyping of adult renal epithelial neoplasms: an experience of 405 cases. Am J Surg Pathol. 2002; 26:281-91. https://doi.org/10.1097/00000478-200203000-00001 PMID:11859199

9. Kuroda N, Toi M, Hiroi M, Enzan H. Review of papillary renal cell carcinoma with focus on clinical and pathobiological aspects. Histol Histopathol. 2003; 18:487-94. https://doi.org/10.14670/HH-18.487 PMID:12647800

10. Patard JJ, Leray E, Rioux-Leclercq N, Cindolo L, Ficarra V, Zisman A, De La Taille A, Tostain J, Artibani W, Abbou CC, Lobel B, Guillé F, Chopin DK, et al. Prognostic value of histologic subtypes in renal cell carcinoma: a multicenter experience. J Clin Oncol. 2005; 23:2763-71.

https://doi.org/10.1200/JCO.2005.07.055

PMID:15837991

11. Xie J, Lin W, Huang L, Xu N, Xu A, Chen B, Watanabe M, Liu C, Huang P. Bufalin suppresses the proliferation and metastasis of renal cell carcinoma by inhibiting the $\mathrm{PI3K} / \mathrm{Akt} / \mathrm{mTOR}$ signaling pathway. Oncol Lett. 2018; 16:3867-73.

https://doi.org/10.3892/ol.2018.9111 PMID:30128000

12. Kondo $T$, Ikezawa E, Takagi T, Kobayashi H, Hashimoto Y, lizuka J, Omae K, Yoshida K, Tanabe K. Negative impact of papillary histological subtype in patients with renal cell carcinoma extending into the inferior vena cava: single-center experience. Int J Urol. 2013; 20:1072-7.

https://doi.org/10.1111/iju.12123 PMID:23421632

13. He Z, Sun $M, K e Y$, Lin R, Xiao $Y$, Zhou $S$, Zhao $H$, Wang $Y$, Zhou $F$, Zhou $Y$. Identifying biomarkers of papillary renal cell carcinoma associated with pathological stage by weighted gene co-expression network analysis. Oncotarget. 2017; 8:27904-14. https://doi.org/10.18632/oncotarget.15842 PMID:28427189

14. Liu K, Ren Y, Pang L, Qi Y, Jia W, Tao L, Hu Z, Zhao J, Zhang $\mathrm{H}$, Li L, Yue H, Han J, Liang W, et al. Papillary renal cell carcinoma: a clinicopathological and wholegenome exon sequencing study. Int J Clin Exp Pathol. 2015; 8:8311-35. PMID:26339402

15. Kovac M, Navas C, Horswell S, Salm M, Bardella C, Rowan A, Stares M, Castro-Giner F, Fisher R, de Bruin 
EC, Kovacova M, Gorman M, Makino S, et al. Recurrent chromosomal gains and heterogeneous driver mutations characterise papillary renal cancer evolution. Nat Commun. 2015; 6:6336.

https://doi.org/10.1038/ncomms7336 PMID:25790038

16. Durinck S, Stawiski EW, Pavía-Jiménez A, Modrusan Z, Kapur P, Jaiswal BS, Zhang N, Toffessi-Tcheuyap V, Nguyen TT, Pahuja KB, Chen YJ, Saleem S, Chaudhuri S, et al. Spectrum of diverse genomic alterations define non-clear cell renal carcinoma subtypes. Nat Genet. 2015; 47:13-21.

https://doi.org/10.1038/ng.3146 PMID:25401301

17. Itzel T, Scholz P, Maass T, Krupp M, Marquardt JU, Strand S, Becker D, Staib F, Binder H, Roessler S, Wang XW, Thorgeirsson S, Müller M, et al. Translating bioinformatics in oncology: guilt-by-profiling analysis and identification of KIF18B and CDCA3 as novel driver genes in carcinogenesis. Bioinformatics. 2015; 31:216-24.

https://doi.org/10.1093/bioinformatics/btu586 PMID:25236463

18. Adams MN, Burgess JT, He Y, Gately K, Snell C, Zhang SD, Hooper JD, Richard DJ, O'Byrne KJ. Expression of CDCA3 Is a Prognostic Biomarker and Potential Therapeutic Target in Non-Small Cell Lung Cancer. J Thorac Oncol. 2017; 12:1071-84.

https://doi.org/10.1016/i.jtho.2017.04.018 PMID:28487093

19. Hu Q, Fu J, Luo B, Huang M, Guo W, Lin Y, Xie X, Xiao S. OY-TES-1 may regulate the malignant behavior of liver cancer via NANOG, CD9, CCND2 and CDCA3: a bioinformatic analysis combine with RNAi and oligonucleotide microarray. Oncol Rep. 2015; 33:1965-75.

https://doi.org/10.3892/or.2015.3792 PMID:25673160

20. Vivian J, Rao AA, Nothaft FA, Ketchum C, Armstrong J, Novak A, Pfeil J, Narkizian J, Deran AD, MusselmanBrown A, Schmidt H, Amstutz P, Craft B, et al. Toil enables reproducible, open source, big biomedical data analyses. Nat Biotechnol. 2017; 35:314-6. https://doi.org/10.1038/nbt.3772 PMID:28398314

21. Love MI, Huber W, Anders S. Moderated estimation of fold change and dispersion for RNA-seq data with DESeq2. Genome Biol. 2014; 15:550. https://doi.org/10.1186/s13059-014-0550-8 PMID:25516281

22. Zhou Y, Zhou B, Pache L, Chang M, Khodabakhshi AH, Tanaseichuk O, Benner C, Chanda SK. Metascape provides a biologist-oriented resource for the analysis of systems-level datasets. Nat Commun. 2019; 10:1523.

https://doi.org/10.1038/s41467-019-09234-6

PMID:30944313
23. Wu M, Sun Y, Wu J, Liu G. Identification of Hub Genes in High-Grade Serous Ovarian Cancer Using Weighted Gene Co-Expression Network Analysis. Med Sci Monit. 2020; 26:e922107. https://doi.org/10.12659/MSM.922107 PMID:32180586

24. Yu G, Wang LG, Han Y, He QY. clusterProfiler: an R package for comparing biological themes among gene clusters. OMICS. 2012; 16:284-7.

https://doi.org/10.1089/omi.2011.0118 PMID:22455463

25. Bindea G, Mlecnik B, Tosolini M, Kirilovsky A, Waldner $M$, Obenauf $A C$, Angell $H$, Fredriksen $T$, Lafontaine $L$, Berger A, Bruneval P, Fridman WH, Becker $C$, et al. Spatiotemporal dynamics of intratumoral immune cells reveal the immune landscape in human cancer. Immunity. 2013; 39:782-95.

https://doi.org/10.1016/i.immuni.2013.10.003 PMID:24138885

26. Szklarczyk D, Gable AL, Lyon D, Junge A, Wyder S, Huerta-Cepas J, Simonovic M, Doncheva NT, Morris JH, Bork $P$, Jensen $\amalg$, Mering CV. STRING v11: proteinprotein association networks with increased coverage, supporting functional discovery in genome-wide experimental datasets. Nucleic Acids Res. 2019; 47:D607-13.

https://doi.org/10.1093/nar/gky1131 PMID:30476243

27. Moch H, Cubilla AL, Humphrey PA, Reuter VE, Ulbright TM. The 2016 WHO Classification of Tumours of the Urinary System and Male Genital Organs-Part A: Renal, Penile, and Testicular Tumours. Eur Urol. 2016; 70:93-105.

https://doi.org/10.1016/i.eururo.2016.02.029 PMID:26935559

28. Huang CS, Tang SJ, Lee MH, Chang Wang CC, Sun GH, Sun $\mathrm{KH}$. Galectin-3 promotes CXCR2 to augment the stem-like property of renal cell carcinoma. J Cell Mol Med. 2018; 22:5909-18.

https://doi.org/10.1111/jcmm.13860 PMID:30246456

29. Liu QJ, Shen HL, Lin J, Xu XH, Ji ZG, Han X, Shang DH, Yang PQ. Synergistic roles of p53 and HIF1 $\alpha$ in human renal cell carcinoma-cell apoptosis responding to the inhibition of mTOR and MDM2 signaling pathways. Drug Des Devel Ther. 2016; 10:745-55. https://doi.org/10.2147/DDDT.S88779 PMID:26937175

30. Peckova K, Martinek P, Pivovarcikova K, Vanecek T, Alaghehbandan R, Prochazkova K, Montiel DP, Hora M, Skenderi F, Ulamec M, Rotterova P, Daum O, Ferda J, et al. Cystic and necrotic papillary renal cell carcinoma: prognosis, morphology, immunohistochemical, and molecular-genetic profile of 10 cases. Ann Diagn Pathol. 2017; 26:23-30. 
https://doi.org/10.1016/i.anndiagpath.2016.10.007 PMID:28038707

31. Michalova K, Steiner P, Alaghehbandan R, Trpkov K, Martinek P, Grossmann P, Montiel DP, Sperga M, Straka L, Prochazkova K, Cempirkova D, Horava V, Bulimbasic $S$, et al. Papillary renal cell carcinoma with cytologic and molecular genetic features overlapping with renal oncocytoma: Analysis of 10 cases. Ann Diagn Pathol. 2018; 35:1-6.

https://doi.org/10.1016/i.anndiagpath.2018.01.010 PMID:30072012

32. Martínez Chanzá N, Xie W, Asim Bilen M, Dzimitrowicz H, Burkart J, Geynisman DM, Balakrishnan A, Bowman IA, Jain R, Stadler W, Zakharia Y, Narayan V, Beuselinck $B$, et al. Cabozantinib in advanced non-clear-cell renal cell carcinoma: a multicentre, retrospective, cohort study. Lancet Oncol. 2019; 20:581-90.

https://doi.org/10.1016/S1470-2045(18)30907-0

PMID: $\underline{30827746}$

33. Choueiri TK, Plimack E, Arkenau HT, Jonasch E, Heng DY, Powles T, Frigault MM, Clark EA, Handzel AA, Gardner H, Morgan S, Albiges L, Pal SK. BiomarkerBased Phase II Trial of Savolitinib in Patients With Advanced Papillary Renal Cell Cancer. J Clin Oncol. 2017; 35:2993-3001.

https://doi.org/10.1200/JCO.2017.72.2967

PMID:28644771

34. Zimpfer A, Maruschke $M$, Rehn $S$, Kundt G, Litzenberger A, Dammert F, Zettl H, Stephan C, Hakenberg OW, Erbersdobler A. Prognostic and diagnostic implications of epithelial cell adhesion/activating molecule (EPCAM) expression in renal tumours: a retrospective clinicopathological study of 948 cases using tissue microarrays. BJU Int. 2014; 114:296-302.

https://doi.org/10.1111/bju.12487 PMID:24215118

35. Kaldany A, Paulucci DJ, Kannappan M, Beksac AT, Anastos H, Okhawere K, Sfakianos JP, Badani KK. Clinicopathological and survival analysis of clinically advanced papillary and chromophobe renal cell carcinoma. Urol Oncol. 2019; 37:727-34.

https://doi.org/10.1016/j.urolonc.2019.05.008 PMID:31174958

36. Qian W, Zhang Z, Peng W, Li J, Gu Q, Ji D, Wang Q, Zhang $Y$, Ji B, Wang $S$, Zhang $D$, Sun Y. CDCA3 mediates p21-dependent proliferation by regulating E2F1 expression in colorectal cancer. Int J Oncol. 2018; 53:2021-33.

https://doi.org/10.3892/ijo.2018.4538

PMID:30226575

37. Zhang $W$, Lu Y, Li X, Zhang J, Zheng L, Zhang W, Lin C, Lin $W$, Li X. CDCA3 promotes cell proliferation by activating the NF-KB/cyclin D1 signaling pathway in colorectal cancer. Biochem Biophys Res Commun. 2018; 500:196-203.

https://doi.org/10.1016/j.bbrc.2018.04.034

PMID:29627567

38. Zhang Y, Yin W, Cao W, Chen P, Bian L, Ni Q. CDCA3 is a potential prognostic marker that promotes cell proliferation in gastric cancer. Oncol Rep. 2019; 41:2471-81.

https://doi.org/10.3892/or.2019.7008 PMID:30816466

39. Yu J, Hua R, Zhang $Y$, Tao $R$, Wang $Q$, Ni Q. DNA hypomethylation promotes invasion and metastasis of gastric cancer cells by regulating the binding of SP1 to the CDCA3 promoter. J Cell Biochem. 2020; 121:142-51.

https://doi.org/10.1002/jcb.28993 PMID: $\underline{31211445}$

40. Li S, Liu X, Liu T, Meng X, Yin X, Fang C, Huang D, Cao $Y$, Weng $H$, Zeng $X$, Wang $X$. Identification of Biomarkers Correlated with the TNM Staging and Overall Survival of Patients with Bladder Cancer. Front Physiol. 2017; 8:947. https://doi.org/10.3389/fphys.2017.00947 PMID:29234286

41. Phan NN, Wang CY, Li KL, Chen CF, Chiao CC, Yu HG, Huang PL, Lin YC. Distinct expression of CDCA3, CDCA5, and CDCA8 leads to shorter relapse free survival in breast cancer patient. Oncotarget. 2018; 9:6977-92.

https://doi.org/10.18632/oncotarget.24059 PMID:29467944

42. Qiu C, Yi YY, Lucena R, Wu MJ, Sun JH, Wang X, Jin QW, Wang Y. F-box proteins Pof3 and Pof1 regulate Wee1 degradation and mitotic entry in fission yeast. J Cell Sci. 2018; 131:jcs202895. https://doi.org/10.1242/ics.202895 PMID:29361524

43. Liu J, Xia L, Wang S, Cai X, Wu X, Zou C, Shan B, Luo M, Wang D. E2F4 Promotes the Proliferation of Hepatocellular Carcinoma Cells through Upregulation of CDCA3. J Cancer. 2021; 12:5173-80.

https://doi.org/10.7150/jca.53708

PMID:34335934

44. Wang Z, Chen S, Wang G, Li S, Qin X. CDCA3 Is a Novel Prognostic Biomarker Associated with Immune Infiltration in Hepatocellular Carcinoma. Biomed Res Int. 2021; 2021:6622437.

PMID:33604380

45. Su P, Wen S, Zhang Y, Li Y, Xu Y, Zhu Y, Lv H, Zhang F, Wang M, Tian Z. Identification of the Key Genes and Pathways in Esophageal Carcinoma. Gastroenterol Res Pract. 2016; 2016:2968106.

PMID:27818681 